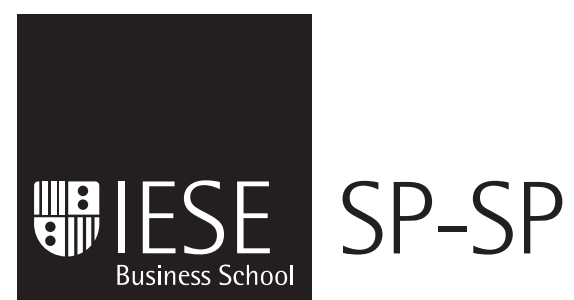

Working Paper

WP no 674

January, 2007

University of Navarra

\title{
STOCHASTIC MARKET SHARING, PARTIAL COMMUNICATION AND COLLUSION
}

Heiko Gerlach 
The Public-Private Center is a Research Center based at IESE Business School. Its mission is to develop research that analyses the relationships between the private and public sectors primarily in the following areas: regulation and competition, innovation, regional economy and industrial politics and health economics.

Research results are disseminated through publications, conferences and colloquia. These activities are aimed to foster cooperation between the private sector and public administrations, as well as the exchange of ideas and initiatives.

The sponsors of the SP-SP Center are the following:

- Accenture

- Ajuntament de Barcelona

- Official Chamber of Commerce, Industry and Navigation of Barcelona

- BBVA

- Diputació de Barcelona

- Garrigues, Abogados y Asesores Tributarios

- Catalan Government (Generalitat de Catalunya)

- Sanofi-Aventis

- Telefonica

- T-Systems

- VidaCaixa

The contents of this publication reflect the conclusions and findings of the individual authors, and not the opinions of the Center's sponsors. 


\title{
STOCHASTIC MARKET SHARING, PARTIAL COMMUNICATION AND COLLUSION
}

\author{
Heiko Gerlach*
}

\begin{abstract}
This paper analyzes the role of communication between firms in an infinitely repeated Bertrand game in which firms receive an imperfect private signal of a common value i.i.d. demand shock. It is shown that firms can use stochastic, inter-temporal market sharing as a perfect substitute for communication in low demand states. Therefore, partial communication in high demand states is sufficient to achieve the most collusive, full communication outcome. And partial communication in low demand state does not improve on the equilibrium without communication. Communication in high demand states allows firms to coordinate their pricing, choose the most efficient uninformed price and avoid price wars. I demonstrate that, under some conditions, consumers are better off with communication among colluding firms.
\end{abstract}

* Department of Economics, University of Auckland

Clasificación JEL: L41, L13, D82

Keywords: Stochastic market sharing, communication, collusion, competition policy.

\footnotetext{
* IESE, SP-SP Center, Barcelona and Department of Economics, University of Auckland, email: h.gerlach@auckland.ac.nz. I would like to thank Simon Anderson, Begoña Dominguez, Joshua Gans, Joe Harrington, Michihiro Kandori, Patrick Rey, Matthew Ryan, Julian Wright, Xavier Vives and seminar participants in Auckland, IESE Barcelona, Melbourne, Pompeu Fabra, Tokyo, Toulouse, Virginia, at EARIE 2005 (Porto), EEA 2005 (Amsterdam) and at the DukeNorthwestern-Texas IO theory conference 2006 for helpful discussions and comments. A previous version of this paper has been circulated under the title "Partial Communication and Collusion with Demand Uncertainty".
} 


\section{STOCHASTIC MARKET SHARING, PARTIAL COMMUNICATION AND COLLUSION}

\section{Introduction}

The detection and prosecution of collusive agreements is the most daunting task of competition policy. Taking collusion at face value, i.e. as market outcomes worse than some competitive benchmark, competition authorities could in principle try to infer collusion from price, quantity and cost data in a given industry. However, as several authors recently argued, inferring collusion from market data is virtually impossible. ${ }^{1}$ In practice, the relevant market information is -for strategic or technical reasons- never fully available to competition authorities. Moreover, quantitative studies of allegedly collusive behavior have proven to be highly sensitive to the specification of the functional forms of the empirical model and therefore not very useful in court. ${ }^{2}$ In some cases, it was pointed out that rather than looking at price levels, an analysis of the evolution of prices in an industry would reduce the data requirements. However, as evidenced in the famous Wood Pulp case $^{3}$, price parallelism is at most a necessary - not a sufficient - condition for the existence of collusion.

Consequently, most competition authorities around the world have adopted the so-called parallelism plus rule. This policy allows prosecution of collusive behavior only in cases where well-founded suspicion can be supported by hard evidence of facilitating practices like communication between firms, resale price maintenance or other institutionalized market design features. In 1998, the European Commission detected the Lombard Club cartel which involved eight Austrian banks in an extremely comprehensive price-fixing scheme including banking products such as interest rates, service fees, money transfers as well as the degree of advertising. ${ }^{4}$ Meetings of the different cartel sub-committees were often triggered by changes in macro-economic variables or the lending rates by the Austrian Central Bank, whereupon the banks promptly met "for the joint reflection of measures to be taken". Eventually, simultaneous

\footnotetext{
${ }^{1}$ These authors include Kühn \& Vives (1995), Kühn (2001), Motta (2004) and Rey (2003).

2 An often cited example are the diametrically opposed conclusions based on the same data set of the US railroad cartel in the 1880's in Porter (1983) and Ellison (1994).

${ }^{3}$ Preparation of Wood Pulp, Case IV/29.725, L85/1, 26.3.85 ECJ Cases C-89, see Motta (2004) for a comprehensive summary.

${ }^{4}$ See the official press release IP-02-844 and the full decision COMP/36.571/D1 at http://europa.eu.int/comm/competition/antitrust/cases
} 
surprise inspections by the Commission unearthed hundreds of documents -minutes of meetings, memoranda, records of telephone conversations, correspondence. In 2002, the Commission imposed fines totaling 124.26 million euros on the eight banks.

The advantage of the parallelism plus rule is that it is based on court-proof, hard evidence. The downside is that its effectiveness crucially hinges on two factors. First, the parallelism plus rule is unable to prosecute collusive outcomes that do not require facilitating practices. And therefore, the less important facilitating practices are for sustaining collusion, the less effective this policy is. Second, competition authorities need to be able to observe the use of facilitating practices. While it seems less obvious to detect information sharing or communication between firms, the Lombard Club case and other recent high-profile cartel cases such as Citric Acids or Vitamins suggest that communication typically leaves hard evidence that can potentially be seized.

In this paper, I concentrate on the first condition and analyze the importance of communication between firms for the sustainability of collusion. While there is some consensus about the fact that communication facilitates collusion, the question here is rather how much communication is actually needed and in which circumstances firms have stronger incentives to communicate. To this end, I consider an infinitely repeated Bertrand game with independent, common value demand fluctuations (low or high). At the beginning of each period, each firm receives a private, independent (over time and firms) signal about the current demand level which is either perfectly informative or not informative at all. The resulting asymmetric information between firms implies that firms no longer agree on the most collusive industry price and have an incentive to engage in communication. At the following communication stage, firms simultaneously send messages to all other firms in the industry. Then firms set prices, the demand level is disclosed and profits are realized. I analyze and compare symmetric perfect public equilibria (SPPE) in three different modes of communication: no communication, full communication (i.e. communication in all states of demand) and partial communication (i.e. communication in one demand state only).

The unobservability of private signals introduces the possibility of opportunistic price cuts in the sense that firms can deviate to prices that are assigned to different signal types. These deviations are not detectable with probability one and impose additional constraints on the optimal organization of collusion. Two such on-schedule deviations have to be accounted for in this context: the deviation of a firm with an informative signal that demand is high (low) to the equilibrium price for firms with an uninformative signal.

The analysis of optimal collusion without communication among firms shows that the most restrictive on-schedule constraint is the one that prevents firms with a high-demand signal from posting the price of an uninformed firm. However, firms have three instruments to relax this condition and the optimal organization of collusion trades off the benefits and costs of these instruments. First, firms can impose price rigidity, i.e. they simply equate the price for the two types in every period. Second, they can distort the uninformed price downwards to make deviations less attractive. And thirdly, firms can start price wars after price distributions they consider to be suspicious of on-schedule deviations. I show that if firms are patient, the leverage of the price war threat is strong enough to induce firms to rely only on the latter two instruments. Firms optimally start price wars after observing uninformed prices from all firms and distort the uninformed price downwards but always above the low-demand monopoly level. The on-schedule constraint for low-demand signal firms is never binding and the optimal organization of collusion approaches the unconstrained maximum without communication if the discount factor goes to one. 
With full communication in low and high demand states the on-schedule constraints are replaced by incentive constraints for communication. If it is (in equilibrium) incentivecompatible to share all information at the communication stage, then at the pricing stage, firms have common knowledge and any deviation is directly observable and punishable. Therefore, sufficiently patient firms can implement the same allocation that a monopoly (with all firms' independent signals) could achieve.

More importantly, the analysis of partial communication then shows that firms can replicate this first-best outcome under full communication with information sharing in high demand states only. The argument to show this equivalence consists of two steps. First, firms can use inter-temporal, stochastic market sharing as a substitute for communication in low demand states. To see this, note that with communication in low demand states, firms share the market evenly (at the monopoly price level) in every low-demand period in which at least one firm receives an informative signal. Without communication, firms with an informative signal undercut their uninformed rivals (to the monopoly price) and all informed firms share the whole market. However, since demand levels and signals are uncorrelated across time and firms, firms have the same probability of being in the winning fraction of firms in each period, i.e. without communication firms share the market stochastically over time. The second part of the argument is to show that the additional on-schedule constraint for low-demand signal firms is not binding in the optimal price schedule.

A similar equivalence result obtains for partial communication in low demand states only. Due to the possibility of stochastic market sharing, the most collusive equilibrium with partial communication in low demand states cannot achieve higher industry profits than collusion without communication.

Finally, I discuss the value of communication for firms and consumers. Stochastic market sharing reduces all rents from communication in low demand states to zero. The value of communication in high demand states can be decomposed in a coordination effect, a price adjustment effect and the gain/loss from avoiding the on-schedule constraint. While for the firms all three effects are positive, for consumers only the first and the third are negative, whereas the price adjustment effect is positive. I demonstrate with an inelastic demand example that the price adjustment effect can indeed dominate and that consumers might be better off if colluding firms communicate in high demand states.

The basic set-up of this paper is based on the seminal work of Rotemberg and Saloner (1986). They consider an industry with observable i.i.d. demand fluctuations and show that the optimal collusive arrangement might involve counter-cyclical price movements. Firms reduce the collusive price in high demand states to counterbalance the stronger incentive to deviate for cartel members. In this paper, I replace the perfect public demand signal with imperfect, independent, private signals and add a communication stage before the pricing decisions. Therefore, my analysis is close to the work of Athey and Bagwell (2001). Their paper considers a repeated game duopoly with inelastic demand in which firms' costs can either be high or low, with independent draws in each period. Each firm knows its own cost realization but not the cost level of its rival. They find an asymmetric perfect public equilibrium that implements firstbest profits in which firms communicate their cost level. Productive (firm) efficiency is achieved by allocating high cost firms a higher future market share. In a similar set-up, Athey, Bagwell and Sanchirico (2004) consider a continuum of cost types and show that the optimal SPPE sacrifices productive efficiency by using a rigid, non-sorting price scheme in order to deter high-cost firms from mimicking low-cost types. The present paper differs from these two 
seminal contributions in at least two important ways. First, firms have private information about a common demand shift and the same cost structure. Thus, the firms' main concern is to coordinate on allocative (firm) efficiency rather than productive efficiency. And secondly, the main focus of this paper is how much communication is necessary to achieve first-best, rather than whether communication can achieve maximum collusive profits.

This paper is also related to the "moral hazard" literature of collusion following the work of Stigler (1964) and Green and Porter (1984). As opposed to the "adverse selection" assumption in this paper, these authors consider situations in which symmetrically informed firms are unable to perfectly observe the behavior of their rivals. If firms receive public signals generated by their price or output choices, the continuation play is always an equilibrium of the repeated game and the dynamic programming technique of Abreu, Pearce and Stacchetti $(1986,1990)$ and Fudenberg, Levine and Maskin (1994) can be applied to establish folk theorems. If, by contrast, firms receive private signals, this recursive structure is destroyed. In this context, Kandori and Matsushima (1998) and Compte (1998) stress the role of communication by generating publicly observable history on which the continuation play can be conditioned. This recovers the recursive structure and allows the proof of folk theorems.

The paper proceeds as follows. The next section introduces the model. The following three sections analyze collusion without, with full and with partial communication. Section 6 compares the results. Section 7 discusses an example and the last section concludes.

\section{The Model}

Consider an infinitely repeated game with $n \geq 2$ firms, labelled $i \in \mathrm{N}=\{1,2, . . n\}$. Firms have constant marginal cost of production $\mathrm{c}>0$ and compete in prices in a market for a homogenous good with stochastic demand. In any period, demand is a function of the market price $p$ and an i.i.d. random variable $\theta \in\{L, H\}$ such that $D(p, \theta)=D^{\theta}(p)$ with $D^{H}(p)>D^{L}(p)$ $\geq 0, \forall p$. The probability of demand being in state $\theta=H$ is given by $\operatorname{Pr}(\theta=H)=\rho, 0 \leq \rho \leq 1$. $^{5}$ Denote monopoly profits in demand state $\theta$ as $\pi^{\theta}(p)=(p-c) D^{\theta}(p)$. I assume that $D^{\theta}(p)$ is twice differentiable, downward sloping and not too convex to ensure concave monopoly profits. Furthermore, I restrict attention to situations where the monopoly price, $p_{\theta}^{*}$, strictly increases with the demand level, i.e. ${ }^{6}$

$$
p_{H}^{*} \equiv \operatorname{argmax} \pi^{H}(p)>p_{L}^{*} \equiv \operatorname{argmax} \pi^{L}(p)
$$

This assumption ensures that there is indeed a coordination problem between firms in the sense that asymmetrically informed firms disagree over the most collusive price in the industry.

At the beginning of each period, firm $i$ receives a private signal $s_{i} \in S \equiv\{L, H, \varnothing\}$ about the state of demand. A firm's signal can either be perfectly informative or not informative at all. The probability for firm $i$ to learn the true state of demand $\theta \in\{L, H\}$ is given by $\operatorname{Pr}\left\{s_{i}=\theta \mid \theta\right\}=\sigma$

\footnotetext{
${ }^{5}$ I shall refer to situations with $p<(>) 1 / 2$ as demand with upward shocks (downward) shocks.

${ }^{6}$ In general, this assumption is satisfied in situations where an increase in demand does not add too many high willingness-to-pay consumers relative to consumers with a lower willingness to pay, i.e. a demand increase is not decreasing the demand slope by too much. Totally differentiating the first order condition yields $d p / d \theta>0$ if $\partial D(p$, $\theta) / \partial \theta+(p-c) \partial^{2} D /(\partial p \partial \theta)>0$. Thus, the assumption excludes demand schedules where $\theta$ enters multiplicatively, $\theta D(p)$ but allows additive formulations like $\theta+D(p)$.
} 
and the probability of getting an uninformative signal in demand state $j$ is $\operatorname{Pr}\left\{s_{i}=\theta \mid \theta\right\}=1-\sigma$. Firms' signals are uncorrelated across firms and independent over time. The parameter $\sigma, 0 \leq \sigma \leq 1$, measures the availability of private demand information for firms.

After observing their private signal, firms communicate by simultaneously announcing a message $m_{i} \in M=\{L, H, \varnothing\}$ to all other firms. ${ }^{7,8}$ The extent to which communication is possible is determined by the degree to which information is verifiable. I assume that firm $i$ with a signal $s_{i} \in\{L, H\}$ can verifiably report this information to its rivals. In other words, firms can prove that they received a high demand or low-demand signal but they cannot prove that they did not receive any information at all. ${ }^{9}$

Communication allows firms to update their belief $b_{i}$ defined as the probability that firm $i$ assigns to the event that demand is high, $b_{i}\left(s_{i}, m\right)=\operatorname{Pr}_{i}\left\{\theta=H \mid\left\{s_{i}, m\right\}\right\}$. It will be useful to refer to $\left(s_{i}, m\right)$ as defining a private information state $\mathcal{I}_{i}$ of firm $i$. As a function of their information state firms choose simultaneously prices $\left(p_{i}\left(\mathcal{I}_{i}\right) . . p_{n}\left(\mathcal{I}_{n}\right)\right)$. The strategy space of firm $i$ for the stage game is given by

$$
\Omega_{i}=\left\{\mu_{i} \mid \mu_{i}: S \rightarrow M\right\} \times\left\{p_{i} \mid p_{i}: S \times M \rightarrow \Re\right\}
$$

and a given strategy $\omega_{i}$ is specified as $\omega_{i}=\left(\mu_{i}\left(s_{i}\right), p_{i}\left(s_{i}, \mu\right)\right)$, a function that maps each possible signal into a message and a function that maps the firm's private signal and the message vector into a price.

It is assumed that at equal prices firms evenly share demand. Thus, firm i's ex post profits for a given price vector $p$ in demand state $\theta \in\{L, H\}$ are

$$
\pi_{\mathrm{i}}(p, \theta)= \begin{cases}0 & \text { if } p_{i}>\underline{p} \\ \pi^{\theta}(\underline{p}) / m & \text { if } p_{i}>\underline{p}\end{cases}
$$

where $\underline{p}$ is the lowest price charged by any firm, $\underline{p} \equiv \min _{i}\left\{p_{i}\right\}$ and $m$ is the number of firms charging price $\underline{p}$. For notational convenience, define the interim profits of firm $i$ at the pricing stage, i.e. after receiving the private signal and messages, as

$$
\Pi_{i}\left(p_{i}, \mathcal{I}_{i}\right) \equiv E\left[\pi_{i}\left(p_{i}, p_{-i}\left(\mathcal{I}_{-i}\right), \mathcal{I}_{i}\right)\right.
$$

The stage game is infinitely repeated creating a play sequence described by $\left\{\theta^{t}, s^{t}, \omega^{t}\right\}$. Firms discount future profits with a common discount factor $\delta$ and maximize the discounted sum of the stage profits. At the end of each period, firms observe the price charged by their rivals and the demand level. However, in the absence of a (verifiable) informative message, it is impossible for a firm to infer their rivals' demand signals. Thus, the game's public history after period $T$

\footnotetext{
7 I prefer to interpret a $\emptyset$-message as no communication between firms as the main focus of this paper is to investigate the extent of communication which is both necessary to sustain collusion and potentially detectable by competition authorities.

${ }^{8}$ Public communication between all industry members precludes the formation of information coalitions within the industry. Throughout the paper I restrict attention to the optimal organization of collusion amongst all firms in the industry.

${ }^{9}$ The main results of the paper do not depend on this assumption. Cheap talk communication imposes additional restrictions on the discount factor, i.e. the patience of firms, but does not affect the optimal organization of collusion.
} 
comprises the demand levels, realized messages and realized prices, i.e $h_{T}=\left\{\theta^{t}, m^{t}, p^{t}\right\}_{t=1}^{T}$, but not the private demand signals $\left\{s^{t}\right\}$. In order to obtain a recursive structure to the problem, I restrict my analysis to symmetric perfect public equilibrium (SPPE). A perfect public equilibrium is a Nash equilibrium in public strategies, i.e. strategies in which firms condition on the public history of the game but not on their own private history (Fudenberg, Levine and Maskin, 1994). A public strategy for this repeated game maps the public history into the set of stage game strategies $\Omega_{i}$. I further impose that firms use symmetric strategies $\omega$ in the sense that firms with the same signal choose the same messages and firms in the same information state set the same price. This implies that after each public history, the continuation value of each firm is the same independent of their current period actions. ${ }^{10}$

\section{Collusion without Communication}

\subsection{The Factored Interim Problem}

I start by analyzing optimal collusion in the absence of communication between firms, i.e. consider $\mu_{i}\left(s_{i}\right)=\emptyset, \forall s_{i} \in S, i \in N$. On the equilibrium path, firm $i$ 's information state $\mathcal{I}_{i}$ at the price setting stage is uniquely determined by its private signal, i.e. $\mathcal{I}_{i}=s_{i}$.

Consider symmetric price vectors $p_{i}(\mathcal{I})=p_{j}(\mathcal{I})=p(\mathcal{I}), i \neq j ; i, j \in N$ and denote $\operatorname{Pr}\{x \mid n\}$ the probability that $x$ out of $\mathrm{n}$ firms are in information state $\mathcal{I}_{i}=\emptyset$. Then, for $p(\varnothing) \leq p(H)$, the $e x$ ante expected profit of firm $i$ in a high demand state can be written as

$$
\Pi_{i}^{\varnothing}(p \mid H) \equiv \operatorname{Pr}\{O \mid n\} \pi^{H}(p(H)) / n+(1-\sigma) \sum_{j=0}^{n-1} \operatorname{Pr}\{j \mid n-1\} \pi^{H}(p(\varnothing)) /(j+1)
$$

Similarly, $e x$ ante expected profits in a low demand state for $p(L) \leq p(\varnothing)$ are

$$
\Pi_{i}^{\varnothing}(p \mid L) \equiv \operatorname{Pr}\{n \mid n\} \pi^{L}(p(\varnothing)) / n+\sigma \sum_{j=0}^{n-1} \operatorname{Pr}\{j \mid n-1\} \pi^{L}(p(L)) /(n-j)
$$

and firms maximize their overall profits $E \Pi_{i}^{\varnothing}(p) \equiv \rho \Pi_{i}^{\varnothing}(p \mid H)+(1-\rho) \Pi_{i}^{\varnothing}(p \mid L)$.

To find the most collusive SPPE, I recur to the recursive dynamic programming technique developed by APS $(1986,1990)$. Any SPPE of the repeated game can be decomposed into a pair of first period price schedules $p(\mathcal{I})$ and continuation values $v(p, \theta)$ that depend on the public history of the first period, i.e. realized prices and the demand level. Conversely, in order for a decomposition pair $(p(\mathcal{I}), v(p, \theta))$ to qualify as a SPPE two necessary and sufficient conditions have to hold. First, an individual firm should have no incentive to deviate from the current period price schedule to a price schedule $p^{\prime}(\mathcal{I})$ given all other firms choose $p(\mathcal{I})$. And second, all continuation values are drawn from the set of SPPE payoff values $V^{*}$. Therefore, the firms' maximization problem can be written as

\footnotetext{
${ }^{10}$ Though restrictive, this assumption reflects situations in which asymmetric continuation values are difficult to implement because future market share allocations might be costly to enforce.
} 


$$
\begin{aligned}
& \max _{p(\mathcal{I}), v(p, \theta))} E \Pi_{i}^{\phi}(p)+\delta E[v(p, \theta)] \text { subject to } \\
& v(p, \theta) \in V^{*}, \forall p \\
& E \Pi_{i}^{\phi}(p)+\delta E[v(p, \theta)] \geq E \Pi_{i}^{\phi}\left(p^{\prime}, p\right)+\delta E\left[v\left(p^{\prime}, p, \theta\right)\right], \forall p^{\prime}
\end{aligned}
$$

The solution to this problem yields the highest possible value of $V^{*}, \bar{v} \equiv \sup \mathrm{V}^{*}$. Since the perpetual repetition of the Nash equilibrium of the stage game is always a SPPE, the set $V^{*}$ is non-empty and its lowest possible value is $\underline{v} \equiv 0$. To convexify the set $V^{*}$ assume that firms have access to a public randomization device at the end of each period. Then, the bang-bang property of optimal continuation values in an equilibrium implies that the value of any SPPE (including the most collusive) can be sustained by a SPPE which after every public history of the first period only uses the two extreme continuation values $\bar{v}$ and $\underline{v}$. In other words, the choice of optimal continuation values can be reduced to assigning a probability $\beta(p, \theta) \in[0,1]$ to every possible public history after period 1 with which firms start a price war, i.e. they revert to the stage game Nash equilibrium forever. With the remaining probability, firms continue to play the current period strategy.

To be implementable, an equilibrium price vector has to resist three types of deviations. First, a firm could choose to deviate off-schedule, i.e. to out-of-equilibrium prices $p^{\prime} \notin p(\mathcal{I})$. These deviations are immediately detected by rivals and can be punished with $\beta(p, \theta)=1$. Thus, it has to hold that, $\forall p^{\prime} \notin p(\mathcal{I})$, and $\forall \mathcal{I}_{i} \in S$,

$$
(1-\delta) \mathrm{II}_{i}\left(p\left(\mathcal{I}_{i}\right), \mathcal{I}_{i}\right)+\delta E\left[v\left(\beta\left(p\left(\mathcal{I}_{i}\right), \theta\right)\right)\right] \geq(1-\delta) \mathrm{II}_{i}\left(p^{\prime}, \mathcal{I}_{i}\right)
$$

Second, firms can deviate to prices that are not equilibrium prices with a strictly positive probability, i.e. deviations that are partially off-schedule. More precisely, if a firm with an uninformative signal deviates to the equilibrium price of a firm with an $H(L)$-signal, it is found out and punished at the end of the period if demand is actually low or, respectively, high. Therefore, it has to hold $\forall \theta^{\prime} \in\{L, H\}$ that

$$
\begin{aligned}
& (1-\delta) I I_{i}(p(\varnothing), \varnothing)+\delta E[v(\beta(p(\varnothing), \theta))] \geq \\
& (1-\delta) I I_{i}\left(p\left(\theta^{\prime}\right), \varnothing\right)+\operatorname{Pr}\left\{\theta=\theta^{\prime}\right\} \delta E\left[v\left(\beta\left(p\left(\theta^{\prime}\right), \theta\right)\right)\right] .
\end{aligned}
$$

Finally, a firm can deviate on-schedule by choosing $p^{\prime} \in p(\mathcal{I} \mid \theta)$. In a SPPE without communication between firms, there are two possible on-schedule deviations: a firm with a $H$-signal or a firm with a $L$-signal could deviate to $p(\varnothing)$. At the end of the first period, firms are never able to infer from the price distribution that with probability one a rival has deviated on-schedule. Consequently, firms have to devise price schedules and continuation values that are robust to on-schedule deviation incentives. A firm with a demand signal $\theta \in\{L, H\}$ does not deviate if

$$
\begin{aligned}
& (1-\delta) I I_{i}\left(p(\theta), \mathcal{I}_{i}=\theta\right)+\delta E\left[v\left(\beta\left(p(\theta), p_{-1}, \theta\right)\right)\right] \geq \\
& (1-\delta) I I_{i}\left(p(\varnothing), \mathcal{I}_{i}=\theta\right)+\delta E\left[v\left(\beta\left(p(\varnothing), p_{-1}, \theta\right)\right)\right]
\end{aligned}
$$


The firms' maximization problem can therefore be rewritten as

$$
\begin{gathered}
\max _{p(\mathcal{I}), \beta(p, \theta))} E \Pi_{i}^{\varnothing}(p)+\delta E[v(\beta(p, \theta))] \text { subject to } \\
0 \leq \beta(p(\theta) \leq 1, \quad \forall p, \theta \\
(\mathrm{OFF}),(\mathrm{POF}) \text { and }(\mathrm{OS}-\theta)
\end{gathered}
$$

\subsection{Equilibrium Analysis}

I assume that firms are sufficiently patient such that off-schedule and partially off-schedule deviations never occur and the constraints (OFF) and (POF) are not strictly binding in equilibrium. I also drop the on-schedule constraint for L-signal firms, (OS-L) and check that in the solution to this reduced maximization problem this constraint is always satisfied.

Firms have three different strategic options to satisfy the remaining constraint (OS-H): price rigidity, price distortions and price wars. The on-schedule constraint is trivially satisfied if firms impose price rigidity,

$$
p(H)=p(\varnothing)
$$

In order to discuss the two other instruments, note that, since (OFF) and (POF) are assumed to be satisfied, the public history after the current period can be summarized by the number of firms posting the uninformed price $p(\varnothing)$. Thus, for notational convenience, denote $\beta_{j}$ the probability of a price war after a period of high demand with $j$ firms posting price $p(\varnothing)$. Then, for $p(\varnothing)<p(H),(\mathrm{OS}-\mathrm{H})$ can be rewritten as

$$
\begin{aligned}
& \sigma^{n-1} \pi^{H}(p(H)) / n+\frac{\delta}{1-\delta} \sum_{j=0}^{n-1} \operatorname{Pr}\{j \mid n-1\}\left(1-\beta_{j}\right) E \Pi_{i}^{\varnothing}(p) \geq \\
& \frac{1-\sigma^{n}}{1-\sigma} \pi^{H}(p(\varnothing)) / n+\frac{\delta}{1-\delta} \sum_{j=0}^{n-1} \operatorname{Pr}\{j \mid n-1\}\left(1-\beta_{j+1}\right) E \Pi_{i}^{\varnothing}(p)
\end{aligned}
$$

or, adding the sums and re-arranging, (OSH-1),

$$
\frac{\delta}{1-\delta} \sum_{j=0}^{n-1} \operatorname{Pr}\{j \mid n-1\}\left(\beta_{j+1}-\beta_{j}\right) E \Pi_{i}^{\varnothing}(p) \geq \frac{1-\sigma}{n(1-\sigma)} \pi^{H}(p(\varnothing))-\frac{\sigma^{n-1}}{n} \pi^{H}(p(H))
$$

The right-hand side ('RHS') of this condition is the expected gain in current period profits from deviating to $p(\varnothing)$ instead of playing the equilibrium price $p(H)$. A deviating firm undercuts all firms receiving a $H$-signal and shares the market (at the lower price $p(\varnothing)$ ) with as many firms as receive an uninformative signal. ${ }^{11}$ The equilibrium strategy only returns strictly positive profits if all other $n-1$ firms also receive an informative signal. Note that the RHS is always positive at $p(H)=p(\emptyset)$ but decreases the more the uninformed price is reduced away from the highdemand monopoly price. In other words, downward price distortions of the uninformed price relax the on-schedule constraint. The left-hand side ('LHS') is the difference in the price war

\footnotetext{
11 The first term on the right-hand side is obtained from simplifying $\sum_{j=0}^{n-1} \operatorname{Pr}\{j \mid n-1\} \pi^{H}(p(\varnothing)) /(j+1)$ using the
} Binomial Theorem.

8 - IESE Business School-University of Navarra 
probabilities from playing the equilibrium price versus deviating to $p(\varnothing)$ times the maximum continuation value. Thus, firms can devise a price $w a r$ vector $\beta$ that punishes price distributions that are more likely to be generated by a deviating firm. Finally note that the uninformed price also enters the LHS. The more the uninformed price is distorted away from the maximizer of $E \Pi_{i}^{\varnothing}(p)$, the less damaging and therefore effective are price wars.

\subsubsection{Unconstrained solution}

As a benchmark, consider the conditions under which the unconstrained solution satisfies the on-schedule constraint.

Lemma 1. The unconstrained solution $p^{*}(\mathcal{D})=\left(p^{*}{ }_{L}, p^{*}(\varnothing), p^{*}{ }_{H}\right)$ where $p^{*}(\varnothing)$ is implicitly defined by

obtains if

$$
(1-\rho)(1-\sigma)^{n} \frac{\partial \pi^{L}(p *(\varnothing))}{\partial p *(\varnothing)}+\rho\left(1-\sigma^{n}\right) \frac{\partial \pi^{H}(p *(\varnothing))}{\partial p *(\varnothing)}=0
$$

$$
\frac{\pi^{H}(p *(\varnothing))}{\pi^{\mathrm{H}}\left(p_{H}^{*}\right)} \leq \frac{\sigma^{n-1}-\sigma^{n}}{1-\sigma^{n}}
$$

It follows directly from (1), the concavity of the profit functions and $p^{*}{ }_{L}<p^{*}{ }_{H}$ the optimal price increases in the firms' demand signal. In particular, firms with a $L$-signal optimally set the lowdemand monopoly price and undercut all firms with an uninformative signal. This means that in a low-demand period, some firms make zero profits while the remaining firms share the market equally at the most collusive price. Similarly, firms with a $H$-signal set the high demand monopoly price but only make positive profits if no rival receives an uninformative signal. Finally, the uninformed price $p(\varnothing)$ is determined by weighing the marginal profits of high and low demand with the respective probability that $p(\varnothing)$ is the industry price in these demand states. In low demand states, the uninformed price becomes effective if no firm receives an informative signal while in high demand states, the uninformed price is chosen if at least one firm receives an uninformative signal. Thus, intuitively, the uninformed price increases in $\rho$ and i and decreases in $\sigma .^{12}$

The unconstrained solution is the global maximizer if $p^{*}(\mathcal{I})$ satisfies (OSH-1) without the use of (costly) price wars, i.e. for $\beta_{i}=0, \forall i$. This holds if the quotient of high demand profits with the uninformed price to high-demand monopoly profits is sufficiently low. The RHS of (2) increases in $\sigma$, decreases in $\mathrm{i}$ and is smaller than $\sigma /(1+\sigma)$ (and therefore always smaller than 1/2). Therefore, together with the comparative statics of the uninformed price, the unconstrained solution is more likely to be satisfied in parameter constellations with $\rho$ and $n$ small and $\sigma$ large.

\footnotetext{
12 Taking the total differential of (1) yields that $d p^{*}(\varnothing) / d \sigma<0$ if $\mathrm{n}(1-\rho)\left(1-\sigma^{\mathrm{n}-1}\left(\left(\partial \pi^{L} / \delta p\right)-\rho n \sigma^{n-1}\left(\left(\partial \pi^{H} / \delta p\right)<0\right.\right.\right.$. Similarly, $\left(d p^{*}(\varnothing) / d n\right)>0$ if $(1-\rho)(1-\sigma)^{n} \log (1-\sigma)\left(\partial \pi^{L} / \partial p\right)-\rho \sigma^{n} \log (\sigma)\left(\left(\partial \pi^{H} / \partial p\right)>0\right.$. Since $\left(\partial \pi^{L}\left(p^{*}(\varnothing)\right) / \partial p^{*}(\varnothing)<0\right.$ and $\partial \pi^{H}\left(p^{*}(\varnothing)\right) / \delta p^{*}(\varnothing)>0$ both inequalities hold.
} 


\subsubsection{Price rigidity}

If the unconstrained solution fails to hold, firms can recur to price rigidity to satisfy the onschedule constraint. The following lemma gives the solution of maximizing the ex ante expected profits subject to (OSH-0).

Lemma 2. If (OSH-O) is strictly binding, the solution to the maximization problem is given by $p(\mathcal{I})=\left(p_{L}^{*}, p^{r}, p^{r}\right)$ where $p^{r}$ is implicitly defined by

$$
(1-\rho)(1-\sigma)^{n} \frac{\partial \Pi^{L}\left(p^{r}\right)}{\partial p^{r}}+\rho \frac{\partial \Pi^{H}\left(p^{r}\right)}{\partial p^{r}}=0
$$

It follows directly from comparing (1) and (3) that the optimal rigid price $p^{r}$ is higher than the uninformed price in the unconstrained solution but lower than the high-demand monopoly price. Thus, ex post prices might be higher or lower compared to the unconstrained solution. Imposing the same price for uninformed firms and firms with a high-demand signal eliminates the possibility of opportunistic price cuts for the latter. However, this solution comes at the cost of ignoring high-demand signals and thereby giving up informational rents in every period. Note that the existence of this rigid price solution is independent of the discount factor and therefore a candidate global maximizer for all values of 6 as long as (2) fails to hold.

\subsubsection{Price distortions and price wars}

First consider the optimal use of price wars for a given price vector. A marginal increase of the probability $\beta_{j}$ of a price war after a price distribution with $j$ uninformed prices has two opposing effects on the LHS of (OSH-1). It decreases the equilibrium continuation value for a $H$-signal firm by the probability that i out of the remaining $n-1$ firms receive an uninformative signal. At the same time, the continuation value after a deviation to $p(\varnothing)$ decreases by the probability that $j-1$ out of the remaining $n-1$ firms receive an uninformative signal. Thus, the overall effect of increasing the price war probability on incentive compatibility is positive only if the probability of facing $j-1$ uninformed rivals is higher than facing $j$ uninformed rivals, or $\operatorname{Pr}\{j-1 \mid n-1\}>\operatorname{Pr}\{j \mid n-1\}$. This potential gain in relaxing the on-schedule constraint has to be traded off with the expected loss in ex ante profits through a marginally more likely price war if in a high-demand period $j$ out of $n$ firms receive an uninformative signal. The following likelihood ratio gives the expected marginal loss in return for marginally relaxing the on-schedule constraint,

$$
\Gamma(\mathrm{j}) \equiv \frac{\rho \operatorname{Pr}\{j \mid n\}}{\operatorname{Pr}\{j-1 \mid n-1\}-\operatorname{Pr}\{j \mid n-1\}}
$$

Denote $\lambda$ the Lagrange multiplier of the on-schedule constraint.

Lemma 3. If (OSH-1) is strictly binding, then the optimal price war strategy can be characterized as follows:

(i) If $\Gamma(j)<\lambda<\Gamma(j-1)$, then $\beta_{i}=0, \forall_{i}, 0 \leq i<j$ and $\beta_{i}=1, \forall_{i}, j \leq i \leq n$.

(ii) If $\lambda=\Gamma(j)$, then $\beta_{j} \in[0,1], \beta_{i}=0, \forall_{i}, 0 \leq i<j$ and $\beta_{i}=1, \forall_{i}, j \leq i \leq n$.

(iii) If $0<\lambda<\Gamma(n)=\rho(1-\sigma)$, then $\beta_{j}=0, \forall_{i}, 0 \leq j \leq n$.

(iv) $\beta_{j}=0$ for $j \leq n(1-\sigma)$. 
Lemma 3 states that for a given shadow price of the on-schedule constraint, it is optimal to start a price war with probability 1 for all numbers of uninformed prices above a certain threshold and not to have any price wars for lower numbers. The reason for this is that the marginal loss per unit of relaxed on-schedule constraint, i.e. $\Gamma(j)$, is decreasing by the number of uninformed equilibrium prices. Thus, if the shadow price $\lambda$ is higher than the likelihood ratio for some $j$ it is always beneficial to increase the price war probability for all $i>j$. Point (i) and (ii) in Lemma 3 apply this idea to two different cases. If the shadow price is identical to the likelihood ratio of the threshold number of uninformed prices, an interior solution $\beta_{j} \in[0,1]$ obtains; if it is higher, a corner solution with $\beta_{j}=1$ holds. Point (iii) states that if the shadow price is below the ex ante probability that a firm remains uninformed in a high demand state, then firms do not use price wars and only rely on price distortions to satisfy the on-schedule constraint. Price wars relax the on-schedule constraint only if the denominator of $\Gamma(j)$ is positive. As point (iv) shows, this is true for all $j$ larger than the maximum likelihood estimate of the number of uninformed signals with $n$ firms which is $n(1-\sigma)$. Consequently, $\Gamma(j)$ goes to infinity as $\mathrm{i}$ approaches $n(1-\sigma)$ and it is -independent of the shadow price- never optimal to start a price war if no more than $n(1-\sigma)$ uninformed prices are observed.

The next step is to analyze the optimal pricing behavior for a given $\lambda$ and the corresponding optimal price war behavior. While at this point the model in its general form becomes intractable for most parameter constellations, it is possible to characterize the solution if firms are sufficiently patient.

Lemma 4. Suppose (2) fails to hold. Then there exists a $\widetilde{\delta}<1$ such that for all $\delta \geq \widetilde{\delta}$ the unique solution to the reduced maximization problem is characterized by

(i) $\beta_{j}=0, \forall j<n$, and $0 \leq \beta_{n} \leq 1$.

(ii) $\quad p(\mathcal{I})=\left(p^{*}{ }_{L}, p^{* * *}(\varnothing), p_{H}^{*}\right)$ with $p^{*}{ }_{L}<p^{* *}(\varnothing)<p^{*}(\varnothing)$.

(iii) for $\delta \rightarrow 1: p^{* * *}(\varnothing) \rightarrow p^{*}(\varnothing)$ and $\beta_{n} \rightarrow 0$.

(iv) (OS-L) is slack.

For sufficiently patient firms, price wars have a strong leverage to relax the on-schedule constraint. In particular, there exists a threshold value on the discount factor above which price wars only need to be triggered with a positive probability after $n$ uninformed prices are observed (point (i)). The optimal degree of downward price distortion takes into account the two effects the uninformed price has on the on-schedule constraint. Decreasing $p(\varnothing)$ away from the high-demand monopoly level relaxes (OSH-1) while moving away from the level of the unconstrained solution $p^{*}(\varnothing)$ reduces the maximum continuation value and thereby makes price wars a less severe punishment. From this it follows that the optimal uninformed price is always below the level of the unconstrained solution (point (ii)).

If firms are more patient, the price war threat becomes even stronger and the optimal price war probability approaches zero as the discount factor goes towards one. At the same time, the cost of distorting the maximal continuation value is increasing and the optimal uninformed price approaches the level of the unconstrained solution (point (iii)). The last point in the above lemma justifies our initial omission of the on-schedule constraint for low-demand signal firms. The leverage of price wars allows firms to sustain an uninformed price strictly above the lowdemand monopoly level. And since a firm with a $L$-signal would never find it optimal to 
deviate upwards, losing its expected share of monopoly profits for a less likely share of smaller industry profits, (OS-L) is not binding.

It is now straightforward to establish the optimal collusion scheme for patient firms without communication.

Proposition 1. Suppose $\delta$ is sufficiently close to 1. If (2) holds, the most collusive SPPE without communication is given by Lemma 1. Otherwise, the most collusive SPPE is given by Lemma 4.

As demonstrated in Lemma 4, the use of price wars allows firms to approach the unconstrained maximum when the discount factor goes to one. Therefore, there must exist a threshold value for $\delta$ above which the price war solution dominates price rigidity. Intuitively, price rigidity ensures incentive compatibility by distorting profits in the current and all future periods whereas price wars and price distortions make relatively more use of future continuation profits. Hence, the relative power of price wars as an incentive mechanism is stronger the more patient firms are.

\section{Collusion with Full Communication}

In this section, I consider equilibria in which firms communicate all the information they receive, i.e. $\mu_{i}\left(s_{i}\right)=s_{i}, \forall s_{i} \in S$. Based on their own signal and the messages received from their competitors, firms update their beliefs about the state of demand. In particular, after the communication stage, firms are in one of three possible information states. With an ex ante probability of $1-(1-\sigma)^{n}$, at least one firm receives an informative signal and sends a message to the other firms. Firms have perfect common knowledge about the state of demand they are in, i.e. $\mathcal{I}_{i}=\mathrm{L}$, or $\mathcal{I}_{i}=\mathrm{H}, \forall_{i}$ with corresponding beliefs of $\mathrm{b}_{\mathrm{i}}\left(\mathcal{I}_{i}=\mathrm{L}\right)=0$ and $\mathrm{b}_{\mathrm{i}}\left(\mathcal{I}_{i}=\mathrm{H}\right)=1$. With the remaining probability $(1-\sigma)^{\mathrm{n}}$ all firms receive uninformative signals and send $\emptyset$-messages to their competitors. In this case firms know that no one knows the demand state, i.e. $\mathcal{I}_{i}=\emptyset, \forall_{i}$ and $b_{i}\left(\mathcal{I}_{i}=\emptyset\right)=\rho{ }^{13}$ Then, for a given symmetric price vector, the $e x$ ante expected profits for firm $i$ in a high-demand period with communication are

$$
\Pi_{i}^{c}(p \mid H) \equiv(1-\operatorname{Pr}\{n \mid n\}) \pi^{H}(p(H)) / n+\operatorname{Pr}\{n \mid n\} \pi^{H}(p(\varnothing)) / n
$$

whereas in a low-demand period one gets

$$
\Pi_{i}^{c}(p \mid L) \equiv(1-\operatorname{Pr}\{n \mid n\}) \pi^{L}(p(L)) / n+\operatorname{Pr}\{n \mid n\} \pi^{L}(p(\varnothing)) / n
$$

Firms maximize their overall profits $\left.E \Pi_{i}^{L H}(p) \equiv \rho \Pi_{i}^{c}(p \mid H)\right) / n+(1-\rho) \Pi_{i}^{c}(p \mid L)$.

Full communication creates common knowledge and the highest possible degree of coordination among firms. More importantly, full equilibrium communication also implies that the on-schedule price deviation constraints are being replaced by the incentive constraints for communication. In other words, if it is incentive-compatible to report a $H$ - or $L$-signal, deviations to the equilibrium price for an uninformative signal become off-schedule and detectable. This means that firms do not need to take into account on-schedule constraints

\footnotetext{
${ }^{13}$ For simplicity, I shall use the same notation for information states in all four classes of equilibria, although in each type of communication equilibrium an information state is defined in a different way.
} 
when they devise the most collusive pricing strategy. However, the optimal price vector must provide incentives to communicate truthfully and resist off-schedule constraints.

Lemma 5. The price vector maximizing firms' ex ante profits with full communication is given by $p^{c}(\mathcal{I})=\left(p_{L}^{*}, p^{c}(\varnothing), p_{H}^{*}\right)$ where $p^{c}(\varnothing)$ is implicitly defined by

$$
(1-\rho) \frac{\partial \pi^{L}\left(p^{c}(\varnothing)\right)}{\partial \mathrm{p}^{c}(\varnothing)}+\rho \frac{\partial \pi^{H}\left(p^{c}(\varnothing)\right)}{\partial \mathrm{p}^{\mathrm{c}}(\varnothing)}=0
$$

The optimal price strategy with full communication is straightforward. If at least one firms receives an informative signal (and communicates), all firms set the complete information monopoly price for the respective demand state and share the market. If no firm receives a signal, firms share the market at an intermediate price equal to the ex ante monopoly price without demand signals.

The price vector in Lemma 5 is sustainable if firms have no incentive to deviate at the communication stage and/or at the pricing stage. The following proposition discusses the conditions for which this holds true. Denote $\delta^{c}$ the threshold value above which a firm would not deviate from its equilibrium price given it is common knowledge that demand is high.

Proposition 2. If $\delta \geq \delta^{c}$, then the price vector $p^{c}(\mathcal{I})$ from Lemma 5 can be supported in a SPPE with full communication.

At the pricing stage, firms have the strongest incentive to deviate in sub-games where it is common knowledge that demand is high, i.e. in sub-games following at least one $H$-message. Proposition 2 implies that if firms are sufficiently patient not to deviate in these price subgames, then they also have no incentive to deviate at the communication stage. To see this suppose firm $i$ receives a high-demand signal but deviates to a ø-message and no other firms sends a $H$-message, then all of the deviating firm's rivals set the uninformed price. However, undercutting this price is less profitable than undercutting the high-demand monopoly price and for $\delta \geq \delta^{\mathrm{c}}$, undercutting is always dominated by setting the uninformed price. Thus, the deviating firm is better off sending a $H$-message at the communication stage and sharing the market at the monopoly price. A similar argument applies to the communication incentives of $L$-signal firms who, for $\delta \geq \delta^{c}$, are always better off sharing the market at the monopoly price and continuing to collude rather than not informing their rivals and undercutting them to the monopoly level.

\section{Collusion with Partial Communication}

\subsection{Collusion with Communication in High Demand States}

I refer to equilibria with partial communication as situations where firms communicate in one state of demand but not in the other. As it turns out, the analysis of the previous two sections greatly simplifies these intermediate cases of communication. First, consider the class of equilibria in which firms only communicate if they receive a high-demand signal, i.e. $\mu_{i}(H)=$ $H \wedge \mu_{i}(L)=\mu_{i}(\varnothing)=\varnothing$. 
Following the communication stage, there are two types of price sub-games and firms can be in one of three information states. With an ex ante probability of $\rho\left(1-(1-\sigma)^{n}\right)$, at least one firm receives a $H$-signal, communicates it and firms have common knowledge that they are in a high-demand period, i.e. $\mathcal{I}_{i}=H \forall i$ and $b_{i}\left(\mathcal{I}_{i}=H\right)=1$. With the remaining probability, all firms receive either a $L$ - or a $\emptyset$-signal and send uninformative messages. In this sub-game, a firm with a $L$-signal has private information that demand is low, i.e. $\mathcal{I}_{i}=L$ and $b_{i}\left(\mathcal{I}_{i}=L\right)=0$. Firms receiving an uninformative private signal and ø-messages from all other firms $\left(\mathcal{I}_{i}=\varnothing\right)$ update their belief according to

$$
b_{i}\left(\mathcal{I}_{i}=\varnothing\right)=\frac{\rho(1-\sigma)^{n-1}}{1-\rho+\rho(1-\sigma)^{n-1}}
$$

Note that with this definition of the information states and the equilibrium communication behavior, firms' ex ante expected profits in a low demand state without communication are the same as in section 3, i.e. $\Pi_{i}^{\varnothing}(p \mid L)$ and the expected profits in a high demand state are the same as in section $4 .{ }^{14}$ Therefore, firms maximize their expected overall profits of $E \Pi_{i}^{H}(p) \equiv \rho \Pi_{i}^{c}$ $(p \mid H)+(1-\rho) \Pi_{i}^{\varnothing}(p \mid L)$.

Lemma 6. The price vector that maximizes ex ante expected profits with partial communication in high demand states is given by $p^{c}(\mathcal{I})$ from Lemma 5.

The optimal organization of collusion with partial communication in high demand states is the same -modulo the definition of the information states- as under full communication. Two observations explain this equivalence result. First, the expected profits in low demand states are the same with and without communication as long as $p(L) \leq p(\varnothing)$. To see this, note that $p(L)$ becomes the effective industry price in both situations if at least one firm receives a $L$-signal, otherwise the industry price is $p(ø)$. With communication, all firms share the market evenly in every low-demand period; without communication, all firms with a $L$-signal share the market by undercutting their uninformed rivals. However, given that signals are uncorrelated across firms and period, each firm has the same probability of being in this winning fraction of firms. In other words, without communication in low demand states, firms share the market stochastically over time and this stochastic market sharing is a perfect substitute for communication. Therefore, the objective of the maximization problem is the same as with full communication.

Secondly, and as detailed in the previous section, communication eliminates on-schedule and partially off-schedule constraints. If it is (in equilibrium) incentive-compatible to communicate in high demand states, then any deviation from $p(H)$ at the price stage becomes detectable. Therefore, provided communication incentives, firms can drop the on-schedule constraint (OSH) and maximize $E \Pi_{i}^{H}(p)$ subject to off-schedule deviations, the partially off-schedule deviation from $p(ø)$ to $p(L)$ and the on-schedule constraint for $L$-signal firms, (OS-L). It follows, however, from Lemma 5 that $p^{c}(\varnothing)>p^{c}(L)=p^{*}(L)$, i.e. (OS-L) is not binding and sufficiently patient firms can achieve the unconstrained maximum. Thus, the lemma follows and it remains to verify the communication incentives.

\footnotetext{
${ }^{14}$ In equilibrium, $p(\varnothing)$ and $p(L)$ only occur in the price sub-game following $\emptyset$-messages while $p(H)$ is exclusively chosen in the price sub-game following at least one H-message. Therefore, maximizing ex ante and interim (i.e. after communication) expected profits is equivalent and for expositional reasons I shall use the former.
} 
Proposition 3. If $\delta \geq \max \left\{\delta^{\mathrm{c}}, \delta^{\mathrm{c}}(\varnothing)\right\}$, then $p^{\mathrm{c}}(\mathcal{I})$ is sustainable in a SPPE with partial communication in high demand states.

The two conditions that place lower bounds on the threshold discount factor follow from the pricing stage. Like in the equilibrium with full communication, the discount factor has to be sufficiently high to prevent undercutting after high demand communication $\left(\delta \geq \delta^{\mathrm{c}}\right)$. In contrast to the full communication case, here, firms also have to account for the partially off-schedule deviation of a firm in information state $\mathcal{I}_{i}=\varnothing$ to $p^{c}(L)$. This deviation is attractive since the absence of a high demand message means that firms have a stronger belief that demand is actually low. It is shown in the appendix that $\delta^{c}(\varnothing)$ is the binding threshold whenever $\mathrm{b}_{\mathrm{i}}\left(\mathcal{I}_{\mathrm{i}}=\varnothing\right)$ is sufficiently small. Then, collusion with partial communication is harder to sustain than with full communication.

As long as the two conditions on the discount factor in Proposition 3 hold, firms also have the incentive to send $H$-messages at the communication stage. The argument is similar to the previous section. Given that a price deviation from a common knowledge high demand state is not profitable for sufficiently patient firms, firms prefer to inform rivals about high demand rather than share the market with uninformed firms at the price stage.

\subsection{Collusion with Communication in Low Demand States}

Finally, consider equilibria where firms report a low-demand signal but not a high-demand signal. After the communication stage, there are two types of price sub-games on the equilibrium path. With an ex ante probability of $(1-\rho)\left(1-(1-\sigma)^{n}\right)$ at least one firm receives a L-signal, communicates it and firms have common knowledge that they are in a low-demand period, i.e. $\mathcal{I}_{i}=L \forall i$. With the remaining probability, all firms receive either an $H$ - or $\emptyset$-signal and send uninformative messages. A firm with a $\mathrm{H}$-signal has private information that demand is high $\left(\mathcal{I}_{i}=H\right)$ while after an uninformative private signal and $\emptyset$-messages from all other firms $\left(\mathcal{I}_{i}=\varnothing\right)$, firm $i$ updates its belief according to

$$
b_{i}\left(\mathcal{I}_{i}=\varnothing\right)=\frac{\rho}{\rho+(1-\rho)(1-\sigma)^{n-1}}
$$

Ex ante expected profits in high demand states without communication are as defined in section 3 and profits in low demand states with communication are as in section 4 . Thus, with partial communication in low demand states, firms maximize

$$
E \Pi_{i}^{L}(\mathrm{p}) \equiv \rho \Pi_{i}^{\varnothing}(\mathrm{p} \mid \mathrm{H})+(1-\rho) \Pi_{i}^{c}(\mathrm{p} \mid \mathrm{L})
$$

Equilibrium communication in low demand states eliminates the on-schedule constraint for $L$-signal firms and the partially off-schedule constraint for deviations from $p(\varnothing)$ to $p(L)$. Hence, firms maximize their expected profits subject to (OS-H), off-schedule deviations and the partially offschedule deviation from $p(\varnothing)$ to $p(H)$.

Proposition 4. Suppose $\delta$ is sufficiently close to 1. If (2) holds, the most collusive SPPE with partial communication in low demand states is given by Lemma 1. Otherwise, the most collusive SPPE is given by Lemma 4. 
This second equivalence result follows from a similar argument to the one in the previous section. Modulo the definition of the information states and for a given communication in low demand states, sufficiently patient firms de facto solve the same maximization problem as without communication. Due to the possibility of stochastic market sharing, communication cannot improve firms' expected profits in low demand states and the objectives of the maximization problems are the same. And while in the absence of communication firms have to take into account two more constraints, (OS-L) and (POF) for deviation to $p(L)$, both of these constraints are actually not binding in the optimal solution of section 3. Therefore, partially communicating firms optimally recur -if required- to the same organization of collusion, i.e. the use of price wars and price distortions, to prevent on-schedule deviations from H-signal firms.

Finally, to see that firms have indeed incentives to communicate L-signals, a similar argument to the case with full communication applies. Sufficiently patient firms prefer to communicate and share the market at the low-demand monopoly price rather than undercut uninformed rivals and end collusion or share the market at the higher uninformed price level.

\section{The Value of Communication}

Denote the optimal expected discounted profits with full, partial and no communication as $V^{L H}$, $V^{H}, V^{L}$ and $V^{\emptyset}$, respectively.

Proposition 5. For sufficiently patient firms, it holds that

$$
V^{\emptyset}=V^{L}<V^{H}=V^{L H}
$$

and

$$
p_{L}^{*}<p^{c}(\varnothing)<p^{\emptyset}(\varnothing)<p_{H}^{*}
$$

The two equalities in part (i) of Proposition 5 summarize the main results of the previous sections. Firms do not require communication in low demand states if they rely on stochastic market sharing. As a consequence, partial communication in the low demand state cannot improve on the equilibrium without communication and partial communication in high demand states achieves the same profit as full communication. Communication in high demand states is valuable to firms for three reasons. First, communication makes on-schedule deviations impossible for firms with high-demand signals and firms do not need to recur to costly price wars and price distortions to ensure incentive compatibility. To see the two other gains from communication, define $\pi^{\emptyset}(p(\varnothing))=\rho \pi^{H}(p(\varnothing)) / n+(1-\rho) \pi^{L}(p(\varnothing)) / n$ as the expected profit of a firm at the uninformed price $p(\varnothing)$ in the absence of any demand information. Then take the difference between expected profits with full communication and without communication (at the unconstrained maximum) and re-arrange as follows

$$
E \Pi_{i}^{L H}\left(p^{c}\right)-E \Pi_{i}^{\phi}\left(p^{\varnothing}\right)=\underbrace{E \Pi_{i}^{L H}\left(p^{\varnothing}\right)-E \Pi_{i}^{\emptyset}\left(p^{\phi}\right)}_{\text {gains from coordination }}+\underbrace{(1-\sigma)^{n}\left(\pi^{\varnothing}\left(p^{c}(\varnothing)\right)-\pi^{\varnothing}\left(p^{\varnothing}(\varnothing)\right)\right)}_{\text {gains from price adjustment }}
$$

The first term on the RHS is the difference in profits at the (unconstrained) optimal price vector without communication. At equal prices, stochastic market sharing implies that firms make the same profits in low demand states with or without communication and, consequently, this term reduces to the profit difference in high demand states. Communication in high demand states avoids uninformed firms undercutting informed firms. Hence, the monopoly outcome is achieved more often with communication (with probability $\left.1-(1-\sigma)^{n}\right)$ than without communication 
(with probability $\sigma^{n}$ ) and the first term on the RHS can be understood as the gains from coordination in high demand states. The second term is the effect of adjusting the uninformed price optimally to the amount of additional information that is available to firms via communication. This term is positive because from (4) it follows that $p^{c}$ maximizes $\pi^{\emptyset}(p(\varnothing))$. Without communication, firms anticipate that in high-demand periods the uninformed price might undercut informed firms who set the high-demand monopoly price. Therefore, firms put relatively more weight on the high demand state and choose a higher uninformed price compared to full communication (compare (1) and (4)). From this, part (ii) of the proposition follows.

The above result implies that whether communication facilitates collusion does not necessarily depend on how much information is exchanged among firms but on the content of information. For examples, in industries with upward demand shocks (i.e. low $\rho$ ), firms communicate more often if they partially communicate in low demand states compared to partial communication in high demand states only. Nevertheless, partial communication in high demand states is more collusive in the sense that it leads to higher industry profits.

Although competition policy is not explicitly modeled in this framework, ${ }^{15}$ the above results invite some comments. In application of the "parallelism plus" rule, competition authorities require evidence of communication to prosecute collusion. If there is the possibility that communication might be detected, part (i) of Proposition 5 suggests that firms would optimally react by either not communicating at all or by communicating in high demand states only. Thus, on the one hand, the above results reduce the scope of the "parallelism plus" rule since less evidence is produced. On the other hand, communication is most likely to occur in high demand states and this might provide helpful guidance in the search for evidence.

Finally, let me turn to consumer surplus. It is clear that consumer surplus can be decomposed into the same three components as industry profits and it follows without further calculations that the coordination effect and the elimination of the on-schedule constraint via communication are negative for consumers. However, part (ii) of Proposition 5 implies that communication leads to a lower uninformed price and therefore the price adjustment effect of communication is positive for consumers. Thus, without additional assumptions on the demand structure, the impact of communication on consumer surplus cannot be assessed unambiguously. The next section considers this trade-off for the case of an inelastic demand.

\section{An Example: Inelastic Demand}

In this section, I briefly present the results of the model for a specific demand example in order to discuss the impact of communication on consumer surplus. Consider an industry with a unit mass of identical customers, each one with an inelastic demand of $D^{\theta}(p)=1$ for $p \leq v_{\theta}$ and $D^{\theta}(p)=0$ otherwise. ${ }^{16}$ Assume $c<v_{L}<v_{H}$ and denote $V \equiv v_{H}-v_{L}$. The remainder of the model is as before. Define the following threshold values

\footnotetext{
15 There are indeed very few papers that consider an active competition authority in a repeated game context. Notable exceptions are Harrington $(2004,2005)$ who analyzes the optimal dynamic pricing behavior of firms under the threat of detection and penalties.

${ }^{16}$ Other functional forms do not yield closed-form solutions for the SPPE without communication. As usual, one possible interpretation of the inelastic demand assumption is a procurement auction where the buyer splits the order between suppliers with the same bid.
} 


$$
\begin{aligned}
& \bar{\rho}_{1} \equiv \frac{\left(v_{L}-c\right) \sigma\left(1-\sigma^{n}\right)}{\left(v_{L}-c\right)\left(\sigma\left(1-\sigma^{n}\right)+(1-\delta)\left(\sigma-\sigma^{n}\right)\right)+\sigma V\left(1-(1-\delta(1-\sigma)) \sigma^{n-1}\right)} \\
& \bar{\rho}_{2} \equiv \frac{\left(v_{L}-c\right)(1-\sigma)^{n}}{\left(v_{L}-c\right)(1-\sigma)^{n}+V\left(1-\sigma^{n}\right)}, \quad \bar{V}=\frac{\left(1-\sigma^{n-1}\right)\left(v_{L}-c\right)}{\sigma^{n-1}(1-\sigma)}
\end{aligned}
$$

and adapt the results on the optimal SPPE without communication from section 3 to the inelastic demand case.

Lemma 7. Assume demand is inelastic. If $\delta$ is sufficiently large, then the optimal SPPE without communication is characterized as follows:

(i) If $V \leq \bar{V}$ and $\rho \leq \bar{\rho}_{1}$, then $p^{* *}(\varnothing)=v_{L}, \beta\left(N_{\varnothing}=i\right)=0, \forall i=0 . . n-1$ and

$$
\beta\left(N_{\varnothing}=n\right)=\frac{(1-\delta) \sigma^{n-1}(\bar{V}-V)}{\delta(1-\sigma)^{n-1}\left(v_{L}-c+\rho \sigma^{n} V\right)}
$$

(ii) if $V \geq \bar{V}$ and $\rho \leq \bar{\rho}_{2}$, then $p^{* *}(\varnothing)=v_{L}$, and $\beta\left(N_{\varnothing}=i\right)=0, \forall i$;

(iii) otherwise, $p^{* *}(\varnothing)=v_{H}$ and $\beta\left(N_{\varnothing}=i\right)=0, \forall i$.

The results in Lemma 7 are driven by the fact that the inelastic demand structure makes expected profits linear in prices. As a consequence, the unconstrained maximizer for the uninformed price is either $p(\varnothing)=v_{L}$ or $p(\varnothing)=v_{H}$. The lower price obtains for $\rho \leq \bar{\rho}_{2}$, i.e. for a low probability of high demand and a small difference in willingness-to-pay in high and low demand. The unconstrained solution holds, if (2) holds, which is the case for $\mathrm{V} \geq \bar{V}$. Part (ii) and part (iii) for $\mathrm{V} \geq \bar{V}$ of the lemma follow.

For sufficiently high $\delta$ and $\mathrm{V} \geq \bar{V}$ there are two candidate maximizers, price rigidity and price wars. The linearity of profits implies that the unconstrained solution $p(\varnothing)=v_{H}$ coincides with the price rigidity solution which is clearly optimal for $\rho \leq \bar{\rho}_{2}$. The optimal price war strategy for sufficiently patient firms includes $p(\emptyset)=v_{L}$ and a price war after $n$ uninformed prices. Price wars are more costly if $\rho$ and $V$ are high and comparing the candidate solutions yields that the price war regime dominates the price rigidity solution for $\rho \leq \bar{\rho}_{1} \leq \bar{\rho}_{2}$. Note that for $\delta$ towards $1, \bar{\rho}_{1}$ converges to $\bar{\rho}_{2}$, the price war probability goes to zero and the unconstrained solution obtains for all parameter values. This equilibrium regime discussion is summarized in Figure 1 where $\delta$ is assumed to be sufficiently high such that the price war solution is feasible for all values of $\rho$ and $V$. 


\section{Figure 1}

SPPE with Inelastic Demand

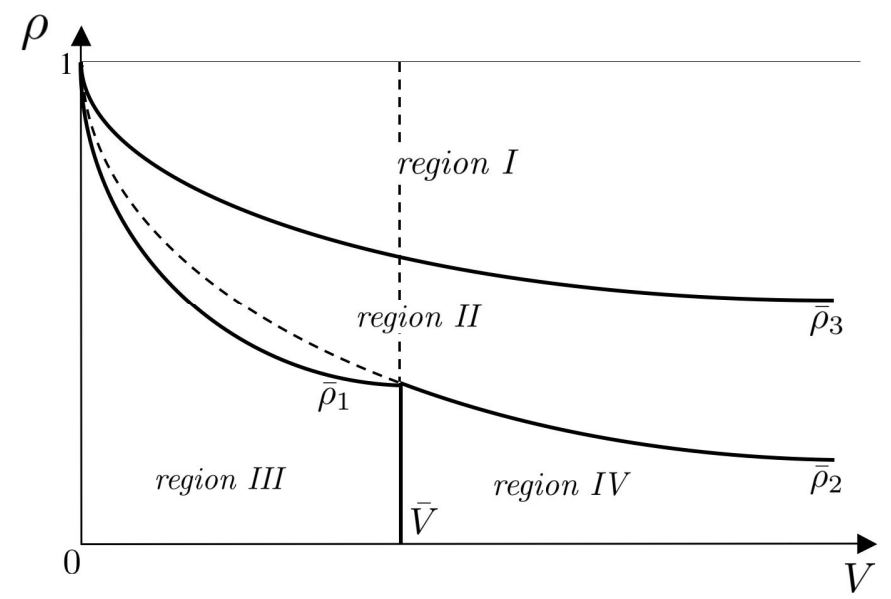

Next reconsider the most collusive SPPE with (full) communication.

Lemma 8. Assume demand is inelastic. If $\delta$ is sufficiently large, then the optimal SPPE with communication implies that if $\rho \leq \bar{\rho}_{3} \equiv\left(v_{L}-c\right) /\left(v_{L}-c+V\right)$, then $p^{c}(\varnothing)=v_{L}$, otherwise, $p^{c}(\varnothing)=v_{H}$.

With communication in high demand states, firms optimally choose $p(\emptyset)=v_{H}$ if $\rho$ is large and the profit margin in high demand states (denominator of $\bar{\rho}_{3}$ ) is high relative to the profit margin in low demand states (numerator).

Since $\bar{\rho}_{3}$ is larger than the two threshold values on $\rho$ from Lemma 7 , the parameter space in Figure 1 is divided into four regions $(I-I V)$ with different equilibrium behaviors with and without communication. The last proposition compares consumer surplus with and without communication in these parameter regions.

Proposition 6. Assume demand is inelastic and $\delta$ sufficiently large. For all parameter values in region II, consumers are strictly better off with communication among firms. In regions III and IV consumers prefer no communication. In region I, they are indifferent.

This result reflects the trade-off between coordination effect, price adjustment effect and the avoiding of price war with communication in high demand states. To see this, note that with an inelastic demand and monopoly prices for firms in information states $H$ and $L$, consumers only make a surplus if the uninformed price is at $v_{L}$ while demand is actually high. It follows that the coordination effect (measured at the optimal price schedule without communication) is zero whenever $p^{\emptyset}(\varnothing)=v_{L}$, i.e. in region $I$ and $I I$, and negative otherwise. The price adjustment effect is positive whenever $p^{\mathrm{c}}(\varnothing)<p^{\emptyset}(\varnothing)$, which only holds in region II. Otherwise, it is zero. Finally, communication makes consumers worse off by avoiding price wars in region $I V$ and the proposition follows. The price adjustment effect of communication dominates the coordination and the price war effect for all parameter values in region II. In other words, given that firms collude, consumers are better off with communication among firms if demand uncertainty is high ( $\rho$ intermediate) and the fluctuation $(V)$ between low and high demand is sufficiently large. 


\section{Conclusions}

This paper introduces imperfect, private demand signals and communication in the work of Rotemberg and Saloner (1986) on implicitly colluding oligopolists with fluctuating demand. It is shown that extensive information exchange is not a prerequisite for firms to implement the first-best collusion profits. In particular, in periods of low demand, firms do not need to communicate at all as long as they rely on stochastic, inter-temporal market sharing. In highdemand periods, however, communication is useful to firms for three reasons. First, it eliminates the possibility of opportunistic price cuts and thereby avoids the costly use of price wars and price distortions (price war effect). It increases the probability that firms achieve the most collusive price by avoiding undercutting from uninformed firms (coordination effect). And thirdly, without undercutting, the uniformed price can be adjusted downwards to the level that an uninformed monopolist would choose (price adjustment effect). For consumers, the first two effects are negative while the price adjustment effect is always positive. It is demonstrated that if demand is inelastic, the latter effect may dominate and consumers might be better off with communication among colluding firms.

The implications of these results for competition policy are ambiguous. On the one hand, less need for communication means that less evidence is produced and it is harder to prosecute firms on the basis of the parallelism plus rule. On the other hand, firms are more likely to communicate in high demand states and this could potentially guide competition authorities in their search for evidence.

To conclude, let me briefly discuss the robustness of these results with respect to the modeling choices and sketch two interesting extensions of this framework. The signal accuracy structure used in the model is specific in the sense that firms are either perfectly informed or not informed at all. Noise in the demand signal introduces inefficiency in the firms' use of stochastic market sharing in an obvious way. Without communication in low demand states, the market would not be served by the best informed firm but by the firm with the lowest demand signal. This works against stochastic market sharing and makes communication relatively more profitable. Thus, the effectiveness of stochastic market sharing as a substitute for communication is limited by the noise in the firms' signal.

It is also granted that the results depend on the mode of competition. Stochastic, inter-temporal market sharing is not feasible with quantity-setting oligopolists. Furthermore, quantity competition should reduce firms' incentives to reveal information in high demand situation because a firm's deviation is more profitable the lower the demand expectations of its rivals. However, the main results should -at least to some extent- carry over to collusive pricing with capacity constraints like in Staiger and Wolak (1992).

Two potential extensions of this framework stand out. First, it would be interesting to analyze whether firms have incentives to form informational coalitions and to communicate only within a small group of firms. Firms would have to trade off less information within their coalition with a higher market share if their competitors remain uninformed. And, second, for communicating firms, demand information is a public good and it seems worthwhile to study if and under which circumstances firms actually have incentives to gather information and how this in turn affects their ability to collude. 


\section{Appendix}

\section{Proof of Lemma 3}

Suppose $p(L) \leq p(\varnothing) \leq p(H)$ and denote the RHS of (OSH-1) as

$$
\Delta(p) \equiv \frac{1-\sigma^{n}}{1-\sigma} \pi^{H}(p(\varnothing)) / n-\sigma^{n-1} \pi^{H}(p(H)) / n
$$

and the LHS as

$$
\frac{\delta}{1-\delta} Z(\beta) E \Pi_{i}^{\varnothing}(p) \equiv \frac{\delta}{1-\delta} \sum_{j=0}^{n-1} \operatorname{Pr}\{j \mid n-1\}\left(\beta_{j+1}-\beta_{j}\right) E \Pi_{i}^{\varnothing}(p)
$$

Then the Lagrangian of this reduced maximization problem can be written as

$$
\begin{gathered}
\mathcal{L}=E \Pi_{i}^{\phi}(p(\mathcal{I}))+(1-\rho) \frac{\delta}{1-\delta} E \Pi_{i}^{\phi}(p(\mathcal{I}))+\rho \frac{\delta}{1-\delta} E \Pi_{i}^{\phi}(p(\mathcal{I})) \sum_{j=0}^{n} \operatorname{Pr}\{j \mid n\}\left(1-\beta_{j}\right) \\
+\lambda\left[\frac{\delta}{1-\delta} Z(\beta) E \Pi_{i}^{\varnothing}(p)-\Delta(p)\right]+\sum_{j=0}^{n} \lambda_{\mathrm{j}}^{0} \beta_{j}+\sum_{j=0}^{n} \lambda_{\mathrm{j}}^{1}\left(1-\beta_{j}\right) \\
=\frac{E \Pi_{i}^{\varnothing}(p(\mathcal{I}))}{1-\delta}\left(1-\rho \delta \sum_{j=0}^{n} \operatorname{Pr}\{j \mid n\} \beta_{j}\right)+\lambda\left[\frac{\delta}{1-\delta} Z(\beta) E \Pi_{i}^{\phi}(p)-\Delta(p)\right] \\
+\sum_{j=0}^{n} \lambda_{\mathrm{j}}^{0} \beta_{j}+\sum_{j=0}^{n} \lambda_{\mathrm{j}}^{1}\left(1-\beta_{j}\right)
\end{gathered}
$$

The Kuhn-Tucker condition for $\beta_{j}$ is given by, (K-1),

$$
\frac{\partial \mathcal{L}}{\partial \beta_{j}}=-\rho \frac{\delta}{1-\delta} \operatorname{Pr}\{\mathrm{j} \mid \mathrm{n}\} E \Pi_{i}^{\varnothing}+\lambda \frac{\delta}{1-\delta}[\operatorname{Pr}\{\mathrm{j}-1 \mid \mathrm{n}-1\}-\operatorname{Pr}\{\mathrm{j} \mid \mathrm{n}-1\}] E \Pi_{i}^{\varnothing}+\lambda_{j}^{0}-\lambda_{j}^{1}=0
$$

Complementary slackness requires that $\lambda_{j}^{0} \beta_{j}=0, \lambda_{j}^{0} \geq 0, \lambda_{j}^{1}\left(1-\beta_{j}\right)=0$ and $\lambda_{j}^{1} \geq 0, \forall j$. It is straightforward to check that $\lambda_{j}^{0}=0$ and $\lambda_{j}^{1}>0$, i.e. $\beta_{j}=1$, if $\lambda>\Gamma(j)$ where $\Gamma(j)$ is defined as in the text. It also follows that $\lambda_{j}^{0}=\lambda_{j}^{1} \geq 0$, i.e. $\beta_{j} \in[0,1]$, if $\lambda=\Gamma(j) . \Gamma(j)$ can be simplified to $\Gamma(j)$ $=\rho n \sigma(1-\sigma) /[j-n(1-\sigma)]$ and since $\partial \Gamma(j) / \partial j=-\Gamma(j) /(j-n(1-\sigma))<0$, the lemma follows.

\section{Proof of Lemma 4}

Define $\Phi(\beta)=\sum_{j=0}^{n} \operatorname{Pr}\{j \mid n\} \beta_{j}$. The remaining Kuhn-Tucker conditions are given by

$$
\begin{aligned}
& \frac{\partial \mathcal{L}}{\partial p(L)}=\frac{1-p \delta \Phi(\beta)}{1-\delta} \frac{\partial E \Pi_{i}^{\varnothing}}{\partial p(L)}+\lambda \frac{\delta}{1-\delta} Z(\beta) \frac{\partial E \Pi_{i}^{\varnothing}}{\partial p(L)}=0, \\
& \frac{\partial \mathcal{L}}{\partial p(H)}=\frac{1-p \delta \Phi(\beta)}{1-\delta} \frac{\partial E \Pi_{i}^{\phi}}{\partial p(H)}+\lambda \frac{\partial \Delta}{\partial \mathrm{p}(H)}+\lambda \frac{\delta}{1-\delta} Z(\beta) \frac{\partial \mathrm{E} \Pi_{i}^{\phi}}{\partial p(H)}=0
\end{aligned}
$$




\section{Appendix (continued)}

$$
\begin{aligned}
& \frac{\partial \mathcal{L}}{\partial p(\varnothing)}=\frac{1-p \delta \Phi(\beta)}{1-\delta} \frac{\partial E \Pi_{i}^{\varnothing}}{\partial p(\varnothing)}+\lambda \frac{\delta}{1-\delta} Z(\beta) \frac{\partial E \Pi_{i}^{\varnothing}}{\partial p(\varnothing)}-\frac{\partial \Delta}{\partial p(\varnothing)}=0, \\
& \lambda\left[\frac{\delta}{1-\delta} Z(\beta) E \Pi_{i}^{\varnothing}-\Delta(p)\right]=0, \lambda \geq 0
\end{aligned}
$$

From $\delta E \Pi_{i}^{\phi} / \delta p(L)=\left[(1-\rho)\left(1-(1-\sigma)^{n}\right) / \mathrm{n}\right] \delta \pi_{i}^{L} / \delta p(L)$ and $(\mathrm{K}-2)$ follows $p(L)=p^{*}{ }_{L}$. From $\delta E \Pi_{i}^{\varnothing} / \delta p(H)=\left[\rho \sigma^{n} / n\right] \delta \pi_{i}^{H} / \delta p(H)$ and $\delta \Delta / \delta p(H)=\left[-\sigma^{n-1} / n\right] \delta \pi_{i}^{H} / \delta p(H)$ and (K-3) follows $p(H)=p{ }_{H}$.

Equations (K-4) and (K-5) determine $p(\varnothing)$ and $\lambda$ taking into account that the optimal price war vector $\beta$ is a function of $\lambda$. According to Lemma 3, there are three different optimal regimes of price wars: the interior solution, the corner solution and the solution with price distortions only.

1. Interior solution. Consider situations in which $\lambda=\Gamma(j), \forall \mathrm{j}$ with $n(1-\sigma)<\mathrm{j} \leq n$. In this solution, it has to hold that $\beta_{j} \in[0,1]$ while $\beta_{k}=1, \forall k, j<k \leq i$. Thus,

$$
Z(\beta)=\operatorname{Pr}\{j \mid n-1\}+\beta_{j}[\operatorname{Pr}\{j-1 \mid n-1\}-\operatorname{Pr}\{j \mid n-1\}]
$$

and

$$
\Phi(\beta)=\operatorname{Pr}\{j \mid n\} \beta_{j}+\sum_{i=j+1}^{n} \operatorname{Pr}\{j \mid n\}
$$

In this regime, the equilibrium price $p(\varnothing)$ is derived from (K-4) while $\beta_{\mathrm{j}}$ is determined from (K-4) given $p(\varnothing)$. I first analyze (K-4) and show that (i) $d p(\varnothing) / d \delta>0$ and $d^{2} p(\varnothing) /(d \delta)^{2}<0$. Then I use these results to derive from (K-5) that (ii) $\forall j$ there exists an interval $I_{j}=\left[\underline{\delta}_{j}, \bar{\delta}_{j}\right]$ such that $\beta_{j} \in$ $[0,1]$ if $\delta \in I_{j}$. Finally, I show that (iii) $\bar{\delta}_{j}<1$ for all $j<n$ and that $\bar{\delta}_{n}=1$.

(i) Rewrite (K-4), group all terms with $\beta_{j}$,

$$
\begin{aligned}
& \delta \frac{\partial E \Pi_{i}^{\varnothing}}{\partial p(\varnothing)} \beta_{j}[\lambda(\operatorname{Pr}\{j-1 \mid n-1\}-\operatorname{Pr}\{\mathrm{j} \mid \mathrm{n}-1\})-\rho \operatorname{Pr}\{j \mid n\}] \\
+ & \left(1-\rho \delta \Phi(0) \frac{\partial E \Pi_{i}^{\varnothing}}{\partial p(\varnothing)}-\lambda\left((1-\delta) \frac{\partial \Delta}{\partial p(\varnothing)}-\delta Z(0) \frac{\partial \mathrm{E} \Pi_{i}^{\varnothing}}{\partial p(\varnothing)}=0\right.\right.
\end{aligned}
$$

Note that the first term is zero since the expression in the bracket is zero for $\lambda=\Gamma(j)$. Further define $\Psi \equiv \lambda Z(0)-p \Phi(0)$, Then, $(\mathrm{K}-4)$ reduces to

$$
(1+\delta \Psi) \frac{\partial \mathrm{E} \Pi_{i}^{\varnothing}}{\partial p(\varnothing)}-(1-\delta) \lambda \frac{\partial \Delta}{\partial p(\varnothing)}=0
$$




\section{Appendix (continued)}

Note that $\Psi$ is positive if

$$
\frac{\operatorname{Pr}\{j \mid n-1\} \operatorname{Pr}\{j \mid n\}}{(\operatorname{Pr}\{j-1 \mid n-1\}-\operatorname{Pr}\{j \mid n-1\})} \geq \sum_{i=j+1}^{n} \operatorname{Pr}\{\mathrm{i} \mid \mathrm{n}\}
$$

The RHS and LHS of this inequality are equal to 0 at $j=n$. Take the first differences $\triangle R H S(j) \equiv$ $R H S(j-1)-R H S(j)$ and $\Delta L H S(j) \equiv L H S(j-1)-L H S(j)$. Verify that $\Delta L H S(j) / \Delta R H S(j)>1$ if

$$
\frac{j \sigma}{(j-n(1-\sigma))(j-1-n(1-\sigma))}>0
$$

which always holds for $\mathrm{n}(1-\sigma)<j \leq n$. From $\Psi>0$, (K-4') and $p(\varnothing)<p(H)=p_{H}^{*}$ follows $\partial \Delta / \partial \mathrm{p}(\varnothing)>0$ and $\partial E \Pi_{i}^{\varnothing} / \partial p(\varnothing)>0$. Then totally differentiate (K-4') to derive

$$
\frac{d p(\varnothing)}{d \delta}=-\frac{\Psi \frac{\partial E \Pi_{i}^{\varnothing}}{\partial p(\varnothing)}+\lambda \frac{\partial \Delta}{\partial p(\varnothing)}}{(1+\delta \Psi) \frac{\partial^{2} E \Pi_{i}^{\varnothing}}{(\partial p(\varnothing))^{2}}-(1-\delta) \lambda \frac{\partial^{2} \Delta}{(\partial p(\varnothing))^{2}}}>0
$$

To ensure concavity of the maximization problem, we have to assume that the denominator is negative (which holds if $\delta$ is sufficiently high). The numerator is positive and the positive overall sign follows. Denote the numerator of $d p(\varnothing) / d \delta$ as $f$ and the negative of the denominator as $g$. Then the second derivative is $d^{2} p(\emptyset) /(d \delta)^{2}=[g(\partial f / \partial \delta)-f(\partial g / \partial \delta)] / g^{2}$ where

and therefore $d^{2} p(\varnothing) /(d \delta)^{2}<0$.

$$
\begin{aligned}
(g \partial f / \partial \delta-f \partial g / \partial \delta)= & g \frac{\partial p(\varnothing)}{\partial \delta} f-f\left(-\Psi \frac{\partial^{2} E \Pi_{i}^{\varnothing}}{(\partial p(\varnothing))^{2}}-\lambda \frac{\partial^{2} \Delta}{(\partial p(\varnothing))^{2}}+g \frac{\partial p(\varnothing)}{\partial \delta}\right) \\
& =f\left(\Psi \frac{\partial^{2} E \Pi_{i}^{\phi}}{(\partial p(\varnothing))^{2}}-\lambda \frac{\partial^{2} \Delta}{(\partial p(\varnothing))^{2}}\right)<0
\end{aligned}
$$

(ii) The optimal interior $\beta_{j}$ for a given $p(\varnothing)$ is implicitly defined from (K-5) by

$$
\Omega \equiv(1-\delta) \Delta(p)-\delta Z(\beta) E \Pi_{i}^{\varnothing}=0
$$

Note that $\Omega(\delta=0)>0$ and $\Omega(\delta=1)<0$. Thus, if $\Omega$ is concave in $\delta$ for all $\delta \in[0,1]$, then there exists a unique value $\hat{\delta}_{j}\left(\beta_{j}\right)$ for which $\Omega=0$. The first derivative is

$$
\frac{d \Omega}{d \delta}=-\Delta(p)-Z(\beta) E \Pi_{i}^{\varnothing}+\frac{\partial p(\varnothing)}{\partial \delta}\left[(1-\delta) \frac{\partial \Delta}{\partial p(\varnothing)}-\delta Z(\beta) \frac{\partial E \Pi_{i}^{\phi}}{\partial p(\varnothing)}\right]
$$

and the second derivative is

$$
\begin{gathered}
\frac{d^{2} \Omega}{(d \delta)^{2}}=-\frac{\partial \Delta}{\partial p(\varnothing)} \frac{\partial p(\varnothing)}{\partial \delta}-Z(\beta) \frac{\partial E \Pi_{i}^{\varnothing}}{\partial p(\varnothing)} \frac{\partial p(\varnothing)}{\partial \delta}+\left[(1-\delta) \frac{\partial \Delta}{\partial p(\varnothing)}-\delta Z(\beta) \frac{\partial E \Pi_{i}^{\varnothing}}{\partial p(\varnothing)}\right] \frac{\partial^{2} p(\varnothing)}{(\partial \delta)^{2}} \\
+\frac{\partial\left[(1-\delta) \frac{\partial \Delta}{\partial p(\varnothing)}-\delta Z(\beta) \frac{\partial E \Pi_{i}^{\phi}}{\partial p(\varnothing)}\right]}{\partial \delta} \frac{\partial p(\varnothing)}{\partial \delta}
\end{gathered}
$$




\section{Appendix (continued)}

Note that by $(\mathrm{K}-4)$ the expression in the bracket of the last term in the first derivative is always positive. Thus, the first three summands of the second derivative are negative. From (K-4), it also follows that the bracketed expression is equivalent to $\left[\partial E \Pi_{i}^{\emptyset} / \partial p(\varnothing)\right](1-p \delta \Phi(\beta)) / \lambda$. The first derivative of this expression with respect to $p(\varnothing)$ is always negative and therefore the fourth term in the second derivative is negative. It follows that $\Omega$ is concave and $\hat{\delta}_{j}\left(\beta_{j}\right)$ is the unique value for which $\Omega=0$. Furthermore, it follows that the slope of $\Omega$ at $\delta=\hat{\delta}_{j}$ is negative. Then, taking the total differential of $\Omega$ yields

$$
\frac{d \tilde{\delta}_{j}}{d \beta_{j}}=-\frac{\partial \Omega / \partial \beta_{j}}{\partial \Omega /\left.\partial \delta\right|_{\delta-\hat{\delta}_{j}}}<0
$$

since the numerator is $-\delta(Z(1)-Z(0)) E \Pi_{i}^{\varnothing}<0$. From this and the uniqueness of $\widetilde{\delta}_{j}$, it follows directly that there exists for each $j$ an interval $\left[\tilde{\delta}_{j}\left(\beta_{j}=1\right), \tilde{\delta}_{j}\left(\beta_{j}=0\right)\right]$ in which an interior solution is feasible.

(iii) Finally check that $\Omega\left(\beta_{j}=0, \delta=1\right)=-\delta$ Z (0) $E \Pi_{i}^{\wp}<0$ and so $\widetilde{\delta}_{j}\left(\beta_{j}=0\right)<1$ for all $j<n$. And since $Z(0)=\operatorname{Pr}\{j=n \mid n-1\}=0$ it follows that $\widetilde{\delta}_{j}\left(\beta_{j}=0\right)=1$ for $j=n$. Consequently, for a sufficiently high $\delta$, the only feasible interior solution is the one described in the lemma.

2. Corner solutions. I now show that corner solutions $\Gamma(j)<\lambda<\Gamma(j-1)$, for all $j, n(1-\sigma)<\mathrm{j} \leq n+1$, are not feasible for $\delta$ sufficiently close to 1 . In corner solution $j$, it holds that $\beta_{i}=1, \forall i \geq j$, and $\beta_{i}=0$ otherwise. The price $p(\varnothing)$ is determined by $(\mathrm{K}-5)$ while $\lambda$ adjusts for given $\mathrm{p}(\varnothing)$ to satisfy $(\mathrm{K}-4)$, i.e.

$$
\lambda=\frac{\partial \mathrm{E} \Pi_{i}^{\varnothing} / \partial p(\varnothing)(1-\rho \delta \Phi(1))}{(1-\delta) \partial \Delta / \partial p(\varnothing)-\delta Z(1) \partial \mathrm{E} \Pi_{i}^{\varnothing} / \partial p(\varnothing)}
$$

It is straightforward to verify that numerator and denominator have opposite signs if $\delta$ approaches 1 . Thus $\lambda$ becomes negative and the solution is not feasible. In fact, for $p(\varnothing) \leq p(H)$ $=\mathrm{p}_{\mathrm{H}}$, we have that $\Delta / \partial \mathrm{p}(\varnothing)>0$ and $\partial E \Pi_{i}^{\emptyset} / \partial p(\varnothing)>0$. From the denominator, it follows that there exists an asymptote $\delta<1$ at which $\lambda$ goes to infinity. Hence, a necessary condition for all corner solutions to hold is that $\delta$ is smaller than $\delta$.

3. No price wars solution. Suppose $0<\lambda<\Gamma(n)=\rho(1-\sigma)$. Without price wars $Z(\beta)=\Phi(\beta)=0$, $p(\varnothing)$ solves $(\mathrm{K}-5)$ and $\lambda$ obtains from $(\mathrm{K}-4)$,

$$
\lambda=\frac{\partial \mathrm{E} \Pi_{i}^{\varnothing} / \partial p(\varnothing)}{(1-\delta) \partial \Delta / \partial p(\varnothing)}
$$

As $\delta$ approaches $1, \lambda$ goes to infinity and the solution is not feasible. 


\section{Appendix (continued)}

This completes the proof of point (i) in the lemma. To show the remaining parts, consider (K-4) for $\lambda=\Gamma(n)=p(1-\sigma)$. Check that $Z(\beta)=\operatorname{Pr}\{n \mid n\} \beta_{\mathrm{n}}$ and $\Phi(\beta)=\operatorname{Pr}\{n-1 \mid n-1\} \beta_{\mathrm{n}}$, then (K-4) can be written as

$$
\left(1-p \delta(1-\sigma)^{\mathrm{n}} \beta_{n}\right) \frac{\partial E \Pi_{i}^{\varnothing}}{\partial p(\varnothing)}-\lambda(1-\delta) \frac{\partial \Delta}{\partial p(\varnothing)}+\lambda \delta(1-\sigma)^{\mathrm{n}-1} \beta_{n} \frac{\partial E \Pi_{i}^{\varnothing}}{\partial p(\varnothing)}=0
$$

After substituting in $\lambda=\rho(1-\sigma), \beta_{n}$ cancels out and the condition reduces to

$$
\begin{aligned}
& \frac{\partial E \Pi_{i}^{\varnothing}}{\partial p(\varnothing)}-\rho(1-\sigma)(1-\delta) \frac{\partial \Delta}{\partial p(\varnothing)}=0, \\
& (1-\rho)(1-\sigma)^{n} \frac{\partial \pi^{L}(p *(\varnothing))}{\partial p *(\varnothing)}+\rho\left(1-\sigma^{n}\right) \frac{\partial \pi^{H}(p *(\varnothing))}{\partial p *(\varnothing)}-(1-\delta) \rho\left(1-\sigma^{n}\right) \frac{\partial \pi^{H}(p *(\varnothing))}{\partial p *(\varnothing)}=0, \\
& (1-\rho)(1-\sigma)^{n} \frac{\partial \pi^{L}(p *(\varnothing))}{\partial p *(\varnothing)}+\delta \rho\left(1-\sigma^{n}\right) \frac{\partial \pi^{H}(p *(\varnothing))}{\partial p *(\varnothing)}=0
\end{aligned}
$$

For $\delta=1$, this condition coincides with the condition for the unconstrained solution (1). For smaller $\delta$ there is less weight on the marginal profits in a high demand state and the resulting optimal $p^{* *}(\varnothing)$ is smaller than the unconstrained price $p^{* *}(\varnothing)$. At the same time, for any $\delta>0$, the optimal price $p^{* *}(\varnothing)$ is larger than the low-demand monopoly price. Point (iv) in the lemma follows directly from plugging $p^{* *}(\emptyset)>p_{L}^{*}$ into the on-schedule constraint for L-signal firms in the absence of price wars

$$
\frac{1-(1-\sigma)^{n}}{\sigma n} \pi^{L}\left(p^{*}\right) \geq \frac{1-(1-\sigma)^{n-1}}{n} \pi^{\mathrm{L}}\left(p^{* *}(\varnothing)\right)
$$

which always holds since $\left[1-\sigma-(1-\sigma)^{n}\right] /[n(1-\sigma) \sigma]>0$ and $\pi^{L}\left(p_{L}^{*}\right)>\pi^{L}\left(p^{* *}(\emptyset)\right)$

\section{Proof of Proposition 2}

After the communication stage, there are three possible types of price sub-games on the equilibrium path. Consider the price subgame following a verified message $m_{i}=H$ from at least one firm. Firms charge the equilibrium price $p^{c}(H)$ if

$$
\delta V^{L H} \geq \frac{(n-1)}{n} \pi^{H}\left(p^{c}(H)\right)
$$

where $V^{L H} \equiv E \Pi_{i}^{L H}\left(p^{c}(\mathcal{I})\right) /(1-\delta)$. With at least one $L$ message, firms stick to their equilibrium price $p^{c}(L)$ if

$$
\delta V^{L H} \geq \frac{(n-1)}{n} \pi^{L}\left(p^{c}(L)\right)
$$




\section{Appendix (continued)}

If all firms receive uninformative signals and messages, firms set $p^{c}(\varnothing)$ if

$$
\frac{\rho \pi^{L}\left(p^{c}(\varnothing)\right)+(1-\rho) \pi^{H}\left(p^{c}(\varnothing)\right)}{n}+\delta V^{L H} \geq \rho \pi^{L}\left(p^{c}(\varnothing)\right)+(1-\rho) \pi^{H}\left(p^{c}(\varnothing)\right)
$$

Clearly, (5) implies (6) and (7) and thus yields $\delta$. After out-of-equilibrium outcomes of the communication stage, firms revert to marginal cost pricing from the current period onwards. Then, at the communication stage, $\varnothing$-signal firms always truthfully report their signal. Suppose firm $i$ receives a $H$-signal and deviates to $m_{i}=\emptyset$. If no other firm receives an informative signal, all remaining firms $j \in N, j \neq i$ are in information state $\mathcal{I}_{j}=\emptyset$ and set price $p^{c}(\varnothing)$. The best deviation for firm $i$ is $p^{c}(\varnothing)-\in$. However, this deviation is always dominated for $\delta \geq \delta$. This means that at the communication stage firm $i$ with a $H$-signal sending $m_{i}=\emptyset$ expects

$$
(1-\sigma)^{n-1}\left(\frac{\pi^{H}\left(p^{c}(\varnothing)\right)}{n}+\delta V^{L H}\right)+\left(1-(1-\sigma)^{n-1}\right)\left(\frac{\pi^{H}\left(p^{c}(\mathrm{H})\right)}{n}+\delta V^{L H}\right)
$$

which is strictly dominated by sending $m_{i}=H$ and receiving $\pi^{H}\left(p^{c}(H)\right) / n+\delta V^{L H}$. If firm $i$ with a $L$-signal deviates to $m_{i}=\varnothing$ and no other firm sends a $L$-message, it either prefers to play $p(\varnothing)$ and have a positive continuation value or undercut all firms with $p_{L}^{*}$. The expected

$$
(1-\sigma)^{n-1} \operatorname{Max}\left\{\frac{\pi^{L}\left(p^{c}(\emptyset)\right)}{n}+\delta V^{L H} ; \pi^{L}\left(p^{c}(L)\right)\right\}+\left(1-(1-\sigma)^{n-1}\right)\left(\frac{\pi^{H}\left(p^{c}(\mathrm{~L})\right)}{n}+\delta V^{L H}\right)
$$

which is for $\delta \geq \delta$ and either value of the Max bracket is always dominated by sending $m_{i}=L$ and receiving $\pi^{L}\left(p^{c}(L)\right) / \mathrm{n}+\delta V^{L H}$.

\section{Proof of Proposition 3}

First consider the price-setting stage on the equilibrium path and define $V^{H} \equiv E \Pi_{i}^{H} p^{c}(\mathcal{I}) /(1-\delta)$ $=V^{L H}$. Suppose there was at least one $H$-message. Then, firms set the equilibrium price $p^{c}(H)$ if $\delta \geq \delta$. Second, suppose all firms sent uninformative messages. A firm with a $L$-signal has no incentive to deviate if and only if $\delta \geq \delta$. A firm with a $\varnothing$-signal has an updated belief of $b_{i}(\emptyset)$ and expects equilibrium profits of

$$
b_{i}(\varnothing) \frac{\pi^{H}\left(p^{c}(\varnothing)\right)}{n}+\left(1-b_{i}(\varnothing)\right)(1-\sigma)^{n-1} \frac{\pi^{L}\left(p^{c}(\mathrm{~L})\right)}{n}+\delta V^{H}
$$

Consider profitable deviations for this firm given its rivals either set $p^{c}(L)$ or $p^{c}(\varnothing)$. The partially on-schedule deviation to $p^{c}(L)$ yields

$$
b_{i}(\varnothing) \Pi^{H}\left(p_{c}(L)\right)+\left(1-b_{i}(\varnothing)\right)\left[\frac{1-(1-\sigma)^{n}}{\sigma n} \Pi^{L}\left(\mathrm{p}_{c}(L)\right)+\delta V^{H}\right]
$$




\section{Appendix (continued)}

This deviation is not profitable if

$$
\begin{gathered}
\delta V^{H} \geq b_{\mathrm{i}}(\varnothing)\left[\pi^{H}\left(\mathrm{p}^{c}(L)\right)-\frac{\pi^{H}\left(p_{c}(\varnothing)\right)}{n}\right] \\
+\left(1-b_{i}(\varnothing)\right)\left[\frac{1-(1-\sigma)^{n}}{\sigma} \pi^{L}\left(p^{c}(L)\right)-(1-\sigma)^{n-1} \frac{\pi^{L}\left(p_{c}(\varnothing)\right)}{n}+\delta V^{H}\right]
\end{gathered}
$$

To show that (5) might be more restrictive than (8), compare their respective RHS for $b_{\mathrm{i}}(\emptyset) \rightarrow 1$. The RHS of (5) is larger since

$$
\pi^{H}\left(p^{c}(H)\right)-\pi^{H}\left(p^{c}(L)\right) \geq \frac{\pi^{H}\left(\mathrm{p}^{c}(H)\right)}{n}-\frac{\pi^{H}\left(p^{c}(\varnothing)\right)}{n}
$$

and $p^{c}(L)=p^{*}{ }_{L} \leq p^{c}(\varnothing) \leq p^{c}(H)=p^{*}{ }_{H}$. To show that (5) might be more restrictive than (8), note that for $b_{i}(\varnothing) \rightarrow 0$, the RHS of (8) goes to infinity for $\delta \rightarrow 1$. Two more possible price deviations for a ø-signal firm need to be checked. First, deviating to $p^{\mathrm{c}}(L)-\epsilon$ yields $b_{i}(\varnothing) \pi^{H}\left(p^{\mathrm{c}}(L)+(1-\right.$ $\left.b_{i}(\varnothing)\right) \pi^{L}\left(p^{c}(L)\right.$, which, for $\delta \geq \delta^{c}$, is always dominated by the deviation to $p^{c}(L)$. Second, deviating to a $p^{d}$ with $p^{c}(L)<p^{d}<p^{c}(\varnothing)$ gives

$$
b_{i}(\varnothing) \pi^{H}\left(p^{d}\right)+\left(1-b_{i}(\varnothing)\right)(1-\sigma)^{n-1} \pi^{L}\left(p^{d}\right)
$$

Maximizing with respect to $p^{d}$ yields the same condition as (4) from Lemma 5, i.e. $p^{d}=p^{c}(\varnothing)-\epsilon$. Setting the equilibrium price $p^{c}(\varnothing)$ dominates this deviation if

$$
\delta V^{H} \geq b_{i}(\varnothing) \frac{(n-1)}{n} \pi^{H}\left(p^{c}(\varnothing)\right)+\left(1-b_{i}(\varnothing)\right)(1-\sigma)^{n-1} \frac{(n-1)}{n} \pi^{L}\left(p^{c}(\varnothing)\right)
$$

which always holds for $\delta \geq \delta^{c}$. The only (potentially) profitable deviation at the communication stage is for a $H$-signal to announce $m_{i}=\emptyset$. In this case, with probability $1-(1-\sigma)^{n-1}$, at least one other firm sends a $H$-message and, for $\delta \geq \delta^{c}$, the deviating firm cannot do better than setting $\mathrm{p}^{\mathrm{c}}(H)$ and receiving equilibrium profits. With probability $(1-\sigma)^{n-1}$, no other firm receives a $H$-signal, only uninformative messages are sent and the deviating firm knows that all of its rivals got a ø-signal and set $p^{c}(\varnothing)$. At this point, setting $p^{c}(\varnothing)$ dominates the best deviation to $p^{c}(\varnothing)-\epsilon$ for $\delta \geq \delta^{c}$. However, the maximum deviation profit of $\pi^{H}\left(p^{c}(\varnothing)\right) / n+\delta V^{H}$ is strictly less than the equilibrium profits with $m_{i}=H$ and the proposition follows.

\section{Proof of Proposition 4}

I show that firms have an incentive to communicate in low demand states for a sufficiently high $\delta$. It is straightforward to show that off-schedule deviations at the pricing stage never occur with sufficiently patient firms. In the sub-games in which all firms send uninformative messages, a firm with a ø-signal also has to resist the partially off-schedule deviation to $p^{* *}(H)=p_{H}^{*}$, i.e. it has to hold that

$$
\begin{aligned}
b_{i}(\varnothing)\left[\frac{1-\sigma^{n}}{n(1-\sigma)} \pi^{H}(p(\varnothing))+\right. & \delta V^{L}\left(1-(1-\sigma)^{n-1} \beta_{n}\right]+\left(1-b_{i}(\varnothing)\right)\left[\frac{1-\sigma^{n}}{n(1-\sigma)} \pi^{L}(p(\varnothing))+\delta V^{L}\right] \\
& \geq b_{i}(\varnothing)\left[\frac{\sigma^{n-1}}{n} \pi^{H}\left(p^{* *}(H)\right)+\delta V^{L}\right]
\end{aligned}
$$




\section{Appendix (continued)}

where $V^{L}$ is the maximal expected discounted continuation value. Note that the difference between the first bracket on the LHS and the bracket on the RHS is identical to the constraint (OSH-1). Since (OSH-1) holds with equality, the brackets cancel out and the condition always holds. Now, consider the communication stage. If firm $i$ receives a $L$-signal and deviates by announcing $m_{i}=\emptyset$, then with probability $1-(1-\sigma)^{n-1}$ at least one other firm receives a $L$-signal and sends a $L$-message. This means all firms are in information state $\mathcal{I}_{\mathrm{i}}=L$ and sufficiently patient firms do not deviate from $p^{* *}(L)$. With probability $(1-\sigma)^{n-1}$, no other firm receives a $L$-signal, only uninformative messages are sent and firms set $p^{* *}(\varnothing)$. At this point, a price deviation is never profitable if $\pi^{L}\left(p^{* * *}(\varnothing)\right) / n+\delta V^{L} \geq$ $\pi^{L}\left(p^{* *}(L)\right)$ which always holds for sufficiently patient firms. Therefore sending a $L$-message at the communication stage dominates sending $m_{i}=\emptyset$ since

$$
\frac{\pi^{L}\left(p^{* *}(L)\right)}{n}+\delta V^{L} \geq(1-\sigma)^{n-1} \frac{\pi^{L}\left(p^{* * *}(\varnothing)\right)}{n}+\left(1-(1-\sigma)^{n-1}\right) \frac{\pi^{L}\left(p^{* *}(L)\right)}{n}+\delta V^{L}
$$

for $p^{* *}(L)=p^{*}{ }_{L}<p^{* *}(\varnothing)$. The proposition follows. 


\section{References}

Abreu, D., D. Pearce, and E. Stacchetti (1986), "Optimal cartel equilibria with imperfect monitoring," Journal of Economic Theory, 39, pp. 251-269.

Abreu, D., D. Pearce, and E. Stacchetti (1990), "Towards a theory of discounted repeated games with imperfect monitoring. Econometrica, 58 (5), pp. 1041-1063.

Athey, S. and K. Bagwell (2001), "Optimal collusion with private information," RAND Journal of Economics, 32, pp. 428-465.

Athey, S., K. BAGWELL, and C. Sanchirico (2004), "Collusion and price rigidity," Review of Economic Studies, 71, pp. 317-349.

Compte, 0. (1998), "Communication in repeated games with imperfect private monitoring," Econometrica 66 (3), pp. 597-626.

Ellison, G. (1994), "Theories of cartel stability and the joint executive committee," RAND Journal of Economics, 25, pp. 37-57.

Fudenberg, D., D. Levine, and E. Maskin (1994), "The folk theorem with imperfect public information," Econometrica, 62, pp. 997-1040.

Green, E. and R. H. Porter, (1984), "Noncooperative collusion under imperfect price information," Econometrica, 52, pp. 87-100.

Harrington, J. E. (2004), "Cartel pricing dynamics in the presence of an antitrust authority," RAND Journal of Economics, 4 (35), pp. 651-673.

Harrington, J. E. (2005), "Optimal cartel pricing in the presence of an antitrust authority," International Economic Review, 1 (46), pp. 145-169.

Kandori, M. and H. Matsushima (1998), "Private observation, communication and collusion," Econometrica, 66 (3), pp. 627-652.

KÜHN, K.-U. (2001). Fighting collusion by regulating communication between firms. Economic Policy 16, 167-204.

Kühn, K. U. and X. Vives (1995), "Information exchanges among firms and their impact on competition," Office of Official Publications of the European Community, Luxembourg.

Motta, M. (2004), “Competition Policy: Theory and Practic,” Cambridge University Press.

Porter, R. (1983), “A study of cartel stability: The joint executive committee," Bell Journal of Economics, 14, pp. 301-314.

Rey, P. (2003), "Towards a theory of competition policy. Advances in Economics and Econometrics: Theory and Applications-Eight World Congress”, M. Dewatripont, L.P. Hansen and S. J. Turnovsky (eds.), Econometric Society Monographs, vol. II, n. 36, pp. 82-132.

Rotemberg, J. and G. Saloner (1986), "A supergame-theoretic model of price wars during booms," American Economic Review, 76, pp. 390-407.

Staiger, R. and F. Wolak, (1992), "Collusive pricing with capacity constraints in the presence of demand uncertainty,” RAND Journal of Economics, 23, pp. 203-220.

Stigler, G. (1964), “A theory of oligopoly,” Journal of Political Economy, 72, pp. 44-61. 